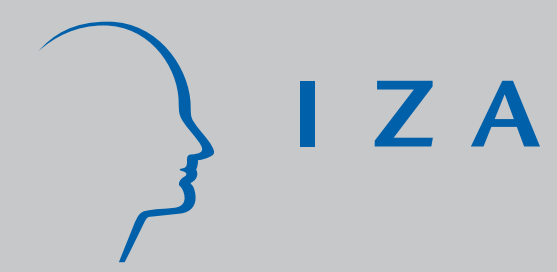

IZA DP No. 1294

A Collective Retirement Model: Identification and Estimation in the Presence of Externalities

Pierre-Carl Michaud

Frederic Vermeulen

September 2004 


\title{
A Collective Retirement Model: Identification and Estimation in the Presence of Externalities
}

\author{
Pierre-Carl Michaud \\ CentER, Tilburg University \\ and IZA Bonn
}

Frederic Vermeulen

CentER, Tilburg University

\section{Discussion Paper No. 1294 \\ September 2004}

\author{
IZA \\ P.O. Box 7240 \\ 53072 Bonn \\ Germany \\ Phone: +49-228-3894-0 \\ Fax: +49-228-3894-180 \\ Email: iza@iza.org
}

\begin{abstract}
Any opinions expressed here are those of the author(s) and not those of the institute. Research disseminated by IZA may include views on policy, but the institute itself takes no institutional policy positions.
\end{abstract}

The Institute for the Study of Labor (IZA) in Bonn is a local and virtual international research center and a place of communication between science, politics and business. IZA is an independent nonprofit company supported by Deutsche Post World Net. The center is associated with the University of Bonn and offers a stimulating research environment through its research networks, research support, and visitors and doctoral programs. IZA engages in (i) original and internationally competitive research in all fields of labor economics, (ii) development of policy concepts, and (iii) dissemination of research results and concepts to the interested public.

IZA Discussion Papers often represent preliminary work and are circulated to encourage discussion. Citation of such a paper should account for its provisional character. A revised version may be available directly from the author. 


\section{ABSTRACT}

\section{A Collective Retirement Model: Identification and Estimation in the Presence of Externalities*}

We study the labor supply dynamics of elderly couples by means of a structural collective model. The model allows for general externalities with respect to spouses' leisure. Preferences and the intrahousehold bargaining process are identified by using panel data with couples and individuals who turned into widow(er)hood in the covered period. The model does not only look at the extensive margin (working versus being retired), but also at the intensive margin (how many hours are worked) and the claiming decision for social security benefits. We apply the model to American households coming from the first five waves of the Health and Retirement Study. We also provide model simulations for two widely discussed reform proposals; more specifically the abolition of the earnings test and the elimination of the spouse benefit. The model simulations reveal only small changes in labor supply of elderly couples.

JEL Classification: D13, H310, J22, J26

Keywords: collective household models, labor supply, retirement, social security, identification

Corresponding author:

Pierre-Carl Michaud

CentER

Tilburg University

P.O. Box 90153

5000 LE Tilburg

The Netherlands

Email: p.c.michaud@uvt.nl

\footnotetext{
* The authors acknowledge the financial support provided through the European Community's Human Potential Programme under contract HPRN-CT-2002-00235, (AGE). We are grateful to James Banks, David Blau, Richard Disney, Arie Kapteyn, Jan van Ours and Arthur van Soest, as well as seminar participants in Tilburg, RAND, CREST, the RTN-AGE workshop in Edesheim and ESEM 2004 Madrid for providing useful comments and suggestions. We also thank Nicole Maestas for helpful discussions on social security rules. Part of this paper was written when the first author was at the RAND Corporation and the Institute for Fiscal Studies London, whose kind hospitality is gratefully acknowledged.
} 


\section{Introduction}

For obvious reasons, considerable attention has been devoted to the economics of retirement. Most industrialized countries were subject to sweeping changes of the labor market during the last decades. Workers retire at younger ages than they used to do, which is coupled to an increasing life expectancy. At the same time, female labor force participation has increased over time, resulting in a shrinking gap between male and female participation rates. These labor market features have their well-known consequences on the social security system (see Gruber and Wise, 1999, and Social Security Administration, 2003, for some background figures).

The bulk of the studies on the economics of retirement concentrated on retirement decisions of older men (see, e.g., Gustman and Steinmeier, 1986, Stock and Wise, 1990, and Rust and Phelan, 1997). Only relatively recently, and following the increased labor force participation of women, attention shifted towards the issue of labor supply behavior of both spouses in elderly couples. Characteristic of couples' labor supply behavior are the coordinated retirement decisions taken. Indeed, the tendency of husbands and wives to retire together, or very shortly after each other, are well documented (see, e.g., Blau, 1998, Gustman and Steinmeier, 2000, 2002, 2004; Maestas, 2001; and Michaud, 2003). Complementarities in spouses' leisure are a likely explanation for such retirement patterns.

Several models describing joint labor supply dynamics of the elderly have been presented. Blau (1998) proposes a model where the household utility function depends on both the husband's and wife's labor supply status; households are thus assumed to behave as single decision makers. One major problem with this so-called unitary approach is that there is much empirical evidence that it does not fit the data very well. Slutsky symmetry and negativity are regularly rejected when confronted with consumption or labor supply data (see Fortin and Lacroix, 1997, Browning and Chiappori, 1998, and Vermeulen, 2004, for some recent examples). Evidence suggests that intra-household bargaining aspects within multi-person households cannot be ignored in general. Gustman and Steinmeier (2000, 2002, 2004) explicitly take into account that older couples are composed of two individuals with own preferences. Household decisions, then, result from a non-cooperative Nash bargaining approach. However, this approach is somewhat controversial since it can lead to equilibrium outcomes that are not Pareto efficient. The question can be asked why spouses would not choose those outcomes that make at least one of them better off without decreasing the welfare level of the other one; especially if one takes into account that spouses in older couples probably know each other's preferences very well, while they are in the repeated game of living in a couple. Another well-known problem occurs when one considers bivariate simultaneous response models which represent equilibria in multi-person discrete games where one allows for externalities; elderly couples' retirement behavior may serve as a typical example. The presence of multiple equilibria implies an incomplete econometric model since nonunique outcomes are predicted for given values of the model's observables and unobservables (see, e.g., Tamer, 2003). This problem is usually solved 
by introducing ad-hoc rules that change the outcome space of the model (see Gustman and Steinmeier, 2000, 2002, 2004). Models based on the unitary approach or on cooperative behavior circumvent this incompleteness problem; well-defined household utility functions associate one, and only one, outcome with a given set of observables and unobservables. Mastrogiacomo, Alessie and Lindeboom (2002) consider a cooperative, and thus complete, retirement model. However, their model is essentially equivalent to models where households act as single decision makers. $^{1}$

We present a structural retirement model that is embedded in the collective approach to household behavior (see, Chiappori, 1988, 1992, for seminal contributions, and Vermeulen, 2002, for an introduction to the approach). More specifically, we assume that spouses in older couples have own preferences over their labor supply and household consumption. Contrary to Gustman and Steinmeier (2000, 2002, 2004), we assume that the household members are involved in a bargaining process that results in Pareto efficient outcomes. Especially for older couples, this assumption seems highly plausible. The assumption has a considerable empirical content too since recent studies have demonstrated that the collective approach turns out to be a valuable alternative to describe household behavior (see Browning and Chiappori, 1998, Chiappori et al., 2002, Cherchye and Vermeulen, 2003, and Vermeulen, 2004).

One important shortcoming of most of the empirical studies within the collective approach is that rather restrictive individual preferences are assumed. More specifically, preferences are usually of the egoistic or the caring type (see Chiappori, 1988 for formal definitions). Basically, these types of preferences imply that an individual's marginal rate of substitution between own leisure and consumption remains unaffected by his or her spouse's labor supply. Thanks to this assumption, both the sharing rule, which governs how a household's means are allocated to the household members, and the individuals' preferences can be identified from labor supply data on couples alone. ${ }^{2}$ As soon as more general preference structures are considered, additional assumptions must be introduced to obtain identification (see Chiappori and Ekeland, 2002). Vermeulen et al. (2003) consider a collective model with externalities going beyond those defined by caring preferences. Identification is obtained by assuming that some aspects of individual preferences are the same across singles and couples. The model is applied to cross-sectional data and involves a rather ad-hoc calibration stage.

We present a novel approach to obtain identification in the presence of general externalities. This is realized by making use of panel data, coming from the Health and Retirement

\footnotetext{
${ }^{1}$ Unitary models are characterized by household utility functions that do not depend on prices (in casu wages). The utility function in Mastrogiacomo et al. (2002) is a weighted average of the utility functions of the individuals in a couple. The weights, however, are fixed; implying that their model cannot be distinguished from a unitary model (see Kooreman and Kapteyn, 1990, and Browning and Chiappori, 1998).

${ }^{2}$ To be more precise, if individuals' preferences are egoistic or caring, then the sharing rule can be identified up to an additive constant, while preferences can be identified up to a translation by means of observed labor supply behavior of couples.
} 
Study (HRS), with both couples and individuals who turned into widow(er)hood during the covered period, in connection with the assumption that preferences do not change, except for possible health shocks, in such an event. We believe that our identification method is much less controversial than assuming that preferences across all types of singles and individuals in couples are the same.

Since we will use our model to conduct simulations of the widely discussed social security reform proposals to eliminate the spouse allowance and the earnings test, it must be able to deal with some specific features on top of allowing for externalities in spouses' leisure. Firstly, a distinction must be made between work and the claiming decision for social security benefits. As has been argued by Rust et al. (2001) and Coile et al. (2003), it may be optimal for individuals to delay claiming and have future benefits increased through the actuarial adjustment. This of course implies some forward-looking behavior by individuals (see also Lazear, 1986 and Gruber and Wise, 2002). Secondly, a proper assessment of the incentives of such institutions as the earnings test and earnings replacement for social security benefits seems only possible if one does not only focus on the extensive margin (working versus being retired), but also on the intensive margin (how many hours are worked). Finally, it is clear that health issues, together with the possible dependence on past choices, may play an important role in the labor supply decisions of the elderly. All these features are given ample attention in our model.

The rest of the paper is structured as follows. In Section 2, we present the collective model that focuses on labor supply behavior of elderly couples. Section 3 describes and illustrates some important features of the data. Empirical results are given in Section 4. In Section 5, we discuss some simulations of social security reforms by means of the structural model. Section 6 concludes.

\section{A collective structural model}

\section{$2.1 \quad$ Theoretical model}

We focus on households that consist of two elderly individuals $m$ and $f$. In what follows, we assume that all consumption in the household is public. We further assume that preferences of each member allow for externalities of the spouse's leisure. Preferences of individual $j$ $(j=m, f)$ can thus be represented by the following direct utility functions:

$$
u_{i t}^{j}=v^{j}\left(l_{i t}^{m}, l_{i t}^{f}, c_{i t}\right)
$$

where $l_{i t}^{j}$ denotes the amount of leisure of individual $j$ in household $i(i=1, \ldots, I)$ at time $t$ $(t=1, \ldots, T)$. The Hicksian public consumption of household $i$ at time $t$ is denoted by $c_{i t}$.

Both household members are involved in a bargaining process that determines the observed 
allocations over leisure and consumption. Following Chiappori (1988, 1992), we assume that this bargaining process results in Pareto efficient allocations. The question can be asked, however, whether household members can commit in the first period to all future allocations, or whether they can only commit to an allocation of resources for the current period (see Mazzocco, 2001). In this paper, we assume that the second case applies: optimal household allocations depend on the bargaining power of the household members in each period, rather than on some lifetime bargaining power.

As usual in the collective setting, observed allocations are assumed to result from the maximization of a weighted linear social welfare function, subject to the household's budget constraint. Before we formally describe this maximization problem, a few important remarks are to be made. Firstly, optimal choices do not only depend on the hours choices of the individuals, but also on their decision to claim social security benefits when they become eligible (see, Rust et al., 2001 and Coile et al., 2003). This claiming decision has an immediate impact on the budget set of eligible individuals since it determines whether or not they will start collecting benefits. It has an additional impact on the budget set through the earnings test, which applies only if an individual collects social security benefits while working. ${ }^{3}$ Household consumption is no real choice variable here, since it is entirely defined by the chosen labor supply and the claiming decision (assuming nonsatiated preferences). In what follows, we will denote the claiming decision by means of the dummy variable $r_{i t}^{j}(j=m, f)$ which indicates whether individual $j$ claimed $\left(r_{i t}^{j}=1\right)$ or did not claim social security benefits $\left(r_{i t}^{j}=0\right)$ at time $t$. A second important remark is that we take into account that the true wage compensation of an individual not only depends on the observed wage rate, but also on the accrual in social security wealth or the implicit social security tax (see, Lazear, 1986 and Gruber and Wise, 2002). Essentially, this implies that by working an additional year without claiming, the current budget set is affected by forgoing benefits, while it simultaneously affects (possibly in a negative way) future payments as captured by the net present value of promised social security benefits. In order to deal with these forward looking aspects in our static model, we will calculate the labor income part of the household budget set on the basis of the true wage compensation. Couples where spouses are faced with positive accruals thus have an expanded budget in comparison to the budget set which would have been obtained by restricting attention to observed wages. Let us denote observed gross wage rates by $w_{i t}^{j *}(j=m, f)$. The true wage rate $w_{i t}^{j}$ used to calculate the labor income is related to the observed wage in the following way:

$$
w_{i t}^{j}=\left(1+a_{i t}^{j}\right) \cdot w_{i t}^{j *} \quad(j=m, f),
$$

where the implicit social security tax $a_{i t}^{j}=\frac{E_{t} S_{t+1}\left(r_{i t}^{j}, l_{i t}^{j}\right)-E_{t} S_{t}\left(r_{i t}^{j}, l_{i t}^{j}\right)}{E_{t} S_{t}\left(r_{i t}^{j}, l_{i t}^{j}\right)}$, with $E_{t}$ the expectations operator (with respect to uncertain life-time) and $S_{t}$ the time-dependent present value of social

\footnotetext{
${ }^{3}$ Note that we do not take into account that benefit losses due to the earnings test are paid at a later age when earnings are below the threshold in our myopic model (see also Appendix A).
} 
security wealth, which is affected by the claiming status and individual leisure. ${ }^{4}$

The household's maximization problem can now be formally described as:

$$
\max _{\left(l_{i t}^{m}, l_{i t}^{f} r_{i t}^{m}, r_{i t}^{f}\right) \in B\left(r_{i t-1}^{m}, r_{i t-1}^{f}, t\right)} u_{i t}^{h}=\mu_{i t} v^{m}\left(l_{i t}^{m}, l_{i t}^{f}, c_{i t}\right)+\left(1-\mu_{i t}\right) v^{f}\left(l_{i t}^{m}, l_{i t}^{f}, c_{i t}\right)
$$

subject to

$$
\begin{aligned}
p_{t} c_{i t} \leq & M_{i t}=F\left(w_{i t}^{m} h_{i t}^{m}+w_{i t}^{f} h_{i t}^{f}+y_{i t}\right. \\
& \left.+b_{t}\left(w_{i t}^{m *} h_{i t}^{m}, w_{i t}^{f *} h_{i t}^{f}, r_{i t}^{m}, r_{i t}^{f}\right)\right),
\end{aligned}
$$

where $p_{t}$ is the price of the public good. The tax function $F$ accounts for the federal income taxes as well as social security contributions to compute the net full income $M_{i t}$. The components that enter gross income are the individuals' true wage rates, non-labor income $y_{i t}$ and labor supply $h_{i t}^{j}=T-l_{i t}^{j}, j=m, f$, where $T$ is the individual's time endowment. ${ }^{5}$ The function $b_{t}$ captures social security benefits (Old Age Social Insurance, OASI), which depend, among others, on both spouses' labor market status and their observed wages through the social security earnings test. Appendix A gives the full details of the computation of the social security benefits available to the household as well as the tax schedule $F$. A detailed account of social security rules is made while a more simplified tax schedule is applied for the federal income tax. Note that the choice variables in the above maximization problem belong to the set $B\left(r_{i t-1}^{m}, r_{i t-1}^{f}, t\right)$. This set combines all possible leisure choices with the claiming decision outcomes. Since an individual is only allowed to claim at the age of 62 , this set depends on time $t$. Moreover, once an individual claimed, he or she cannot undo this decision in the future. In other words, the choice set gets restricted once an individual decided to start collecting benefits (i.e., the only remaining choice are the hours worked). Therefore, the choice set also depends on the past claiming status $r_{i t-1}^{j}(j=m, f)$.

As can be seen from (2), male and female utilities are weighted by respectively $\mu_{i t}$ and $\left(1-\mu_{i t}\right)$. We assume that these weights depend on real wages, non-labor income and other

\footnotetext{
${ }^{4} \mathrm{~A}$ few remarks can be made with respect to the accrual in social security wealth. Firstly, the effect of hours worked on the implicit social security tax is individual specific. E.g., if there is wage replacement for some individual (see Appendix; calculation of Average Indexed Monthly Earnings), then the effect of hours on the accrual will be positive. If the earnings test comes into play, however, then hours worked negatively affect the accrual. Secondly, we consider the accrual in each year where a decision is taken. In the option value model of Stock and Wise (1990), the maximum gain from postponing retirement versus retiring now is focused on. This gain is found by comparing the present values of retiring at each future age versus retiring in the current period. If these present values monotonously vary over time, then the accrual is sufficient to model retirement delay. Note finally, that the accruals are generally small for the sample that we selected.

${ }^{5}$ Many individuals receive a lump sum of private pension benefits when they retire. In order to avoid a bias by taking up this usually large lump sum in the non-labor income $y_{i t}$, we opted to annuitize it such that individuals spread these large pensions over their remaining life years (where life expectancy is set equal to 100). This choice is also supported by Hurd et al. (1998), who show that less than one fifth of the HRS respondents who have private pension rights cash out their entitlements. Moreover, these cashed-out plans only account for about $6 \%$ of all plan dollars involved.
} 
earnings or pension history characteristics influencing the form of the budget set and therefore potentially influencing the individuals' bargaining position within the household. Moreover, welfare weights may also depend on so-called 'distribution factors', which influence individuals' bargaining positions but do not affect their preferences or the household's budget set (see Chiappori, Fortin and Lacroix, 2002). As a consequence, we have $\mu_{i t}=\mu\left(\mathbf{p}_{i t}\right)$, where $\mathbf{p}_{i t}$ is a vector of, say, 'bargaining factors' containing real wages, budget set characteristics and distribution factors. If $\mu_{i t}$ is increasing in $w_{i t}^{m}$, e.g., then the husband's bargaining position improves, following an increase in his true wage. ${ }^{6}$ This implies that he will be able to claim a higher utility than before, which is produced by an intrahousehold allocation that is more favorable to the husband. Because altruism is allowed, this does not necessarily imply that the husband will work less, while the wife will work more than before. Worthy of note is that this model implies a deviation from the traditional unitary model, since the household's 'utility function' now depends on current wages and non-labor income.

A well-known problem of the above general setting with public goods and externalities, however, is that the model is not identified without additional assumptions, even by making use of bargaining factors in the weights (see Bourguignon and Chiappori, 1994, and Chiappori and Ekeland, 2002). The problem is essentially that if marginal utilities are strictly positive for all goods, then there exists a continuum of utility functions and welfare weights that yield the same observed choices. Chiappori and Ekeland (2002) propose restrictions on these marginal utilities to secure identification. They propose to use goods where consumption can be assumed to be exclusive (e.g., males' and females' clothes).

In our context this is not applicable, so we must rely on some other solution. Therefore, in what follows, we will assume that singles, and more specifically widows and widowers, have the same preferences as individuals in couples who have the same sex, and who have similar other personal characteristics like health status. This allows identifying both preferences, as captured by the utility functions $v^{j}$, and welfare weights $\mu_{i t}$ and $\left(1-\mu_{i t}\right)$. In the next section, we show that these restrictions are similar in spirit to conditions imposed in Chiappori and Ekeland (2002). Essentially, we restrict the marginal utility of the partner's leisure to be zero when that spouse dies.

At first sight, this may appear as a strong assumption. However, if one believes that preferences are individual-specific, as is explicitly the case in the collective approach, then it can be argued that preferences can only change via a clear channel following the death of one's partner. An obvious candidate for such a channel is health status that we can control for by modelling heterogeneity in preferences that may change over time. Since it can be argued that widow(er)hood is an exogenous shock to a household (conditional on a set of

\footnotetext{
${ }^{6}$ The assumed dependence of these weights on current real wages is rather innocuous: it simply implies that the bargaining power of an individual remains unchanged, if all current prices and wages are multiplied by a common factor. As a consequence, observed behavior is not affected by the unit in which monetary variables are expressed.
} 
observables such as age and prior health), the assumption of equality of preferences is much more innocent then assuming that all singles would have the same preferences as individuals in couples, irrespective of the fact that they were never married, were divorced or turned into widow(er)hood. Notwithstanding this identification assumption, several sources for differences in behavior between widow(er)s and individuals in couples are allowed. Firstly, widow(er)hood may be followed by a health shock that on its turn may influence preferences. Secondly, opportunity sets can be very different over household types; a fact that is even corroborated by all goods being publicly consumed. Thirdly, in our empirical model, singles' utility functions are conditional on the amount of leisure of the individual of the other sex being equal to the amount corresponding to full-time working hours. For couples, this implicitly implies that living in a couple does not generate utility in its own (apart from a higher income that is publicly consumed). Additional utility of living in a couple compared to being single is, ceteris paribus, only created if a spouse is retired or working part-time. These three features may give rise to quite different labor supply choices of widow(er)s and individuals in couples. We will show below that the panel data at hand is very well-suited to pursue the above identification strategy.

\subsection{Empirical model}

\subsubsection{Individual and collective household utility functions}

Let us now turn to the empirical strategy to apply the above structural model. Specific to this strategy is that it is embedded in a discrete choice framework. This approach assumes that individuals have the choice between only a limited number of labor supply options. The advantage of the approach is that it can easily deal with complex non-linear and non-convex tax schemes; a feature certainly applicable to the social security benefits system.

Assuming that both spouses are confronted with the same choices, let us denote the discrete set of leisure choices by $L=\left\{l_{p} ; p=1, \ldots, P\right\}$. Possible leisure choices $l_{p}$ are equal to $E-h_{p}$, were $E$ is an individual's weekly total time endowment and $h_{p}$ are weekly working hours. Following van Soest (1995), these working hours are multiples of a fixed interval length $I L=$

$\frac{h_{P}}{P-1} ; h_{P}$ being the maximum possible working hours. Hours choices $h_{p}$ are thus equal to $(p-1) I L, p=1, \ldots, P$. In the empirical exercise, the number of working hours choices $P$ is set equal to 4 , while $h_{P}$ is equal to 60 hours. This results in working hours choices that range from 0 to 60 hours, in multiples of 20 hours. Leisure choices are finally obtained by subtracting these working hours from $E$, which, taking account of time needed to sleep and other maintenance tasks, is set equal to 80 . As already discussed before, the set $L$ is only part of the total state space: individuals also have to choose whether or not they will delay claiming social security benefits.

With discrete choice labor supply in a collective setting, one of the main concerns will 
be to postulate individual utility functions which impose coherency through concavity, and further will allow for taste variation in all possible states. Allowing for externalities is also of crucial importance. Therefore, we assume that individuals' preferences are of a modified Cobb-Douglas type and are represented by the direct utility function $(j=m, f)$ :

$$
v^{j}\left(l_{i t}^{m}, l_{i t}^{f}, c_{i t}\right)=\beta_{m}^{j} \ln l_{i t}^{m}+\beta_{f}^{j} \ln l_{i t}^{f}+\beta_{c}^{j} \ln c_{i t}+\beta_{m f}^{j} \ln l_{i t}^{m} \ln l_{i t}^{f} .
$$

These utility functions depend on the spouse's leisure in two ways. First, the spouse's leisure enters in a strongly separable fashion through $\beta_{-j}^{j}$ not affecting marginal tradeoffs between own leisure and consumption. Second, it enters into the marginal utility of own leisure through $\beta_{m f}^{j}$. This second effect is very similar to that considered in Gustman and Steinmeier (2000, $2002,2004)$. We would expect a positive coefficient $\beta_{m f}^{j}$ if marginal utility of leisure increases with leisure of the spouse.

Restricting coherency conditions to own choice variables, utility functions are well-behaved if marginal utilities with respect to own consumption and leisure are positive. Note that the household consumption $c_{i t}$ depends on both spouses' leisure and on their claiming decision. Heterogeneity among individuals is introduced as follows $(j=m, f ;-j \neq j)$ :

$$
\begin{gathered}
\beta_{-j}^{j}=\mathbf{x}_{-j, i t}^{j \prime} \delta_{-j}^{j}, \\
\beta_{j}^{j}=\mathbf{x}_{j, i t}^{j \prime} \delta_{j}^{j}+\alpha_{i}^{j}+\sum_{p=1}^{P-1} \eta_{p}^{j} I\left(l_{i t-1}^{j}=l_{p}\right),
\end{gathered}
$$

where we assume that $\boldsymbol{\alpha}_{i}=\left(\alpha_{i}^{m}, \alpha_{i}^{f}\right)^{\prime}$ is distributed according to a bivariate normal distribution in the population with covariance matrix $\Omega_{\alpha}:\left(\sigma_{\alpha j k}\right)$ for $j, k=m, f$. We thus assume that the above coefficients are linear functions of observed demographic variables like age and health indicators; all included in the vectors $\mathbf{x}_{-j, i t}^{j}$ and $\mathbf{x}_{j, i t}^{j}$. The utility parameter associated with own leisure is also dependent on some unobserved heterogeneity $\alpha_{i}^{j}$ that may influence joint labor supply decisions, and the past labor supply choice as captured by the indicator functions $I$ (.). It should be remarked that this specific heterogeneity structure can be interpreted both as dynamic behavior through preferences depending on past choices and as hours restrictions due to, for example, fixed costs to participation. In our rather myopic collective model, these factors only shape current preferences and do not influence future intrahousehold allocations (see also Lazear, 1986, and Hurd, 1996). We also mirror the heterogeneity structure present in the leisure coefficient $\beta_{j}^{j}$ for the coefficient $\beta_{c}^{j}$ without allowing for a lagged effect of past leisure decisions. Since a positive marginal utility in consumption is crucial we restrict it $a$ priori to be positive.

Since the individual welfare weights, $\mu_{i t}$, have to be between zero and one, we opt for the following functional specification:

$$
\mu_{i t}=\mu\left(\mathbf{p}_{i t}\right)=\frac{\exp \left(\mathbf{p}_{i t}^{\prime} \mu\right)}{1+\exp \left(\mathbf{p}_{i t}^{\prime} \mu\right)} .
$$


In the empirical exercise, the vector of bargaining factors $\mathbf{p}_{i t}$ includes hourly wages, nonlabor income and variables such as the average indexed monthly wage directly linked with the calculation of social security benefits. It is expected that all these variables may influence an individual's bargaining position in the household. The non-labor income will be effectively capital income. The wages considered will be imputed wages that depend implicitly on health, tenure, age and other covariates. We will also include the age difference between spouses in the specification of the weight.

\subsubsection{Identification of preference parameters and welfare weights}

As already mentioned, the above collective model with public goods and externalities cannot be identified on couples' data alone. To illustrate the problem, consider the following collective household utility function that is the weighted average of the individual utility functions $v^{j}\left(l_{i t}^{m}, l_{i t}^{f}, c_{i t}\right)(j=m, f)$ of equation (3) with appropriate weights:

$$
\begin{aligned}
u_{i t}^{h}= & \mu\left(\mathbf{p}_{i t}\right)\left(\beta_{m}^{m} \ln l_{i t}^{m}+\beta_{f}^{m} \ln l_{i t}^{f}+\beta_{c}^{m} \ln c_{i t}+\beta_{m f}^{m} \ln l_{i t}^{m} \ln l_{i t}^{f}\right) \\
& +\left(1-\mu\left(\mathbf{p}_{i t}\right)\right)\left(\beta_{m}^{f} \ln l_{i t}^{m}+\beta_{f}^{f} \ln l_{i t}^{f}+\beta_{c}^{f} \ln c_{i t}+\beta_{m f}^{f} \ln l_{i t}^{m} \ln l_{i t}^{f}\right) .
\end{aligned}
$$

To make the exposition easier, let us assume that the weights are linear in the set of bargaining factors: $\mu\left(\mathbf{p}_{i t}\right)=\boldsymbol{\mu}^{\prime} \mathbf{p}_{i t}$. Next, given the above specification for the household utility function, we get the following restrictions from which to identify the parameters from couples alone:

$$
\begin{aligned}
\eta_{m}\left(\mathbf{p}_{i t}\right) & =\mu\left(\mathbf{p}_{i t}\right) \beta_{m}^{m}+\left(1-\mu\left(\mathbf{p}_{i t}\right)\right) \beta_{m}^{f}, \eta_{f}\left(\mathbf{p}_{i t}\right)=\mu\left(\mathbf{p}_{i t}\right) \beta_{f}^{m}+\left(1-\mu\left(\mathbf{p}_{i t}\right)\right) \beta_{f}^{f} \\
\eta_{c}\left(\mathbf{p}_{i t}\right) & =\mu\left(\mathbf{p}_{i t}\right) \beta_{c}^{m}+\left(1-\mu\left(\mathbf{p}_{i t}\right)\right) \beta_{c}^{f}, \eta_{m f}\left(\mathbf{p}_{i t}\right)=\mu\left(\mathbf{p}_{i t}\right) \beta_{m f}^{m}+\left(1-\mu\left(\mathbf{p}_{i t}\right)\right) \beta_{m f}^{f} .
\end{aligned}
$$

One will note that there are $\mathbf{P}$ restrictions per $\eta_{j}\left(\mathbf{p}_{i t}\right)\left(j=m, f, c, m f ; \mathbf{P}=\operatorname{dim}\left(\mathbf{p}_{i t}\right)\right.$ including a constant) given the interactions between each of the elements of $\mathbf{p}_{i t}$ and the utility components. Therefore, there are $4 \mathbf{P}$ restrictions in total. The number of structural parameters defining preferences and weights equals $\mathbf{P}+8$. Hence, it appears that the model is identified based on the order condition for $\mathbf{P}>2$. This is the case as soon as two elements in $\mathbf{p}_{i t}$ are added on top of a constant, which is essentially the result shown in Kooreman and Kapteyn (1990). However, we can show in this general context that the rank condition fails to be satisfied.

Consider, for example, the following transformed individual utility functions and welfare weights (compare to Chiappori and Ekeland, 2002):

$$
\begin{aligned}
v^{f *}\left(l_{i t}^{m}, l_{i t}^{f}, c_{i t}\right) & =\epsilon v^{f}\left(l_{i t}^{m}, l_{i t}^{f}, c_{i t}\right)+(1-\epsilon) v^{m}\left(l_{i t}^{m}, l_{i t}^{f}, c_{i t}\right), \\
v^{m *}\left(l_{i t}^{m}, l_{i t}^{f}, c_{i t}\right) & =(\epsilon-1) v^{f}\left(l_{i t}^{m}, l_{i t}^{f}, c_{i t}\right)+\epsilon v^{m}\left(l_{i t}^{m}, l_{i t}^{f}, c_{i t}\right), \\
\mu^{*}\left(\mathbf{p}_{i t}\right) & =\frac{\mu\left(\mathbf{p}_{i t}\right)-1-\epsilon}{2 \epsilon-1}, 1-\mu^{*}\left(\mathbf{p}_{i t}\right)=\frac{\epsilon-\mu\left(\mathbf{p}_{i t}\right)}{2 \epsilon-1},
\end{aligned}
$$


where $\epsilon>\max \left\{\mu\left(\mathbf{p}_{i t}\right), 1-\mu\left(\mathbf{p}_{i t}\right)\right\} \backslash\left\{\frac{1}{2}\right\}$. It can now easily be checked that the collective household utility function that is obtained by these transformed utilities and welfare weights results in the same set of restrictions as in (7). In other words, a continuum of structural models (defined by different values of $\epsilon$ ) give rise to the same reduced-form parameters; and therefore the same predicted behavior from couples' data alone.

Key for this non-identification result is that the individual utility functions are strictly increasing in their arguments. Therefore, Chiappori and Ekeland (2002) propose to use exclusive goods to obtain identification in this case. One needs two goods, each of which is exclusive to one of the spouses. What we want to show here is that using couples and widow(er)s serves that purpose without using exclusive goods. To do this, we introduce two dummy variables $k_{i t}^{m}$ and $k_{i t}^{f}$. If an observation $i$ at time $t$ consists of a couple, then both dummies are equal to one. For single men (women), $k_{i t}^{m}\left(k_{i t}^{f}\right)$ equals one, while $k_{i t}^{f}\left(k_{i t}^{m}\right)$ is equal to zero. We can now write the household utility function (with some abuse of notation) as:

$$
\begin{aligned}
u_{*}^{h}\left(\mathbf{y}_{i t}, k_{i t}^{m}, k_{i t}^{f}, \mathbf{p}_{i t} ; \mathbf{z}_{i t}\right)= & \left(1-k_{i t}^{f}\right) v^{m}\left(\mathbf{y}_{i t}, k_{i t}^{f} ; \mathbf{z}_{i t}\right)+k_{i t}^{f} v^{f}\left(\mathbf{y}_{i t}, k_{i t}^{m} ; \mathbf{z}_{i t}\right) \\
& +k_{i t}^{m} k_{i t}^{f} \mu\left(\mathbf{p}_{i t}\right)\left(v^{m}\left(\mathbf{y}_{i t}, k_{i t}^{f} ; \mathbf{z}_{i t}\right)-v^{f}\left(\mathbf{y}_{i t}, k_{i t}^{m} ; \mathbf{z}_{i t}\right)\right),
\end{aligned}
$$

where $\mathbf{y}_{i t}=\left(l_{i t}^{m}, l_{i t}^{f}, c_{i t}\right)^{\prime}$ and $\mathbf{z}_{i t}$ captures all other exogenous variables.

For widows the utility function equals:

$$
u_{*}^{h}\left(\mathbf{y}_{i t}, 0,1, \mathbf{p}_{i t} ; \mathbf{z}_{i t}\right)=v^{f}\left(\mathbf{y}_{i t}, 0 ; \mathbf{z}_{i t}\right)=\beta_{f}^{f} \ln l_{i t}^{f}+\beta_{c}^{f} \ln c_{i t},
$$

with $\partial v^{f} / \partial l_{i t}^{m}=0$. For widowers, we have:

$$
u_{*}^{h}\left(\mathbf{y}_{i t}, 1,0, \mathbf{p}_{i t} ; \mathbf{z}_{i t}\right)=v^{m}\left(\mathbf{y}_{i t}, 0 ; \mathbf{z}_{i t}\right)=\beta_{m}^{m} \ln l_{i t}^{m}+\beta_{c}^{m} \ln c_{i t},
$$

in which case $\partial v^{m} / \partial l_{i t}^{f}=0$.

Finally, for couples we have

$$
\begin{aligned}
u_{*}^{h}\left(\mathbf{y}_{i t}, 1,1, \mathbf{p}_{i t} ; \mathbf{z}_{i t}\right) & =\mu\left(\mathbf{p}_{i t}\right) v^{m}\left(\mathbf{y}_{i t}, 1 ; \mathbf{z}_{i t}\right)+\left(1-\mu\left(\mathbf{p}_{i t}\right)\right) v^{f}\left(\mathbf{y}_{i t}, 1 ; \mathbf{z}_{i t}\right) \\
& =\eta_{m}\left(\mathbf{p}_{i t}\right) \ln l_{i t}^{m}+\eta_{f}\left(\mathbf{p}_{i t}\right) \ln l_{i t}^{f}+\eta_{c}\left(\mathbf{p}_{i t}\right) \ln c_{i t}+\eta_{m f}\left(\mathbf{p}_{i t}\right) \ln l_{i t}^{m} \ln l_{i t}^{f} .
\end{aligned}
$$

From widows and widowers, 4 parameters can be estimated for as many structural parameters. Using these parameters in the four sets of restrictions for couples, enables to separately identify weights from preference parameters. This is because there are 4 remaining preference parameters and $\mathbf{P}$ weight parameters, while there are $4 \mathbf{P}$ parameters that can be estimated.

\subsubsection{Estimation}

Since we assumed away savings, and depending on the number of labor supply choices for both individuals (denoted by $P$ ) and whether or not individuals already claimed, there are maximum $P^{2} \times 4$ possible values of the decision variables for married couples. They involve 
all combinations of both individuals' labor supply and their claiming decision (if they have not claimed yet; cf. supra). Since the budget constraint is potentially non-convex and choices are discrete we need to evaluate utility at maximum $P^{2} \times 4$ points

$$
u^{h}\left(\mathbf{y}_{i t}^{s}, \mathbf{k}_{i t}, \mathbf{p}_{i t} ; \mathbf{z}_{i t}\right)=u_{*}^{h}\left(\mathbf{y}_{i t}^{s}, \mathbf{k}_{i t}, \mathbf{p}_{i t} ; \mathbf{z}_{i t}\right)+\varepsilon_{s i t}
$$

where $\mathbf{k}_{i t}=\left(k_{i t}^{m}, k_{i t}^{f}\right)^{\prime}$ and $\mathbf{y}_{i t}^{s} \in B\left(r_{i t-1}^{m}, r_{i t-1}^{f}, t\right)$. We add some measurement or optimization error term for each alternative assumed to be independent and identically distributed across alternatives with type 1 extreme value distribution (GEV(1)). Note that for singles only maximum $P \times 2$ states are observed. Since we model the budget set carefully we will be able to take account of survivor benefits and changes in non-labor income following the death of the spouse. Therefore, we allow for a structural shift through the budget set but not directly through the utility function, which remains the same after the death of one's partner (if no health shocks are present).

For an observation $i$, the probability of observing the sequence $\mathbf{y}_{i,-0}=\left(\mathbf{y}_{i 1}^{\prime}, \ldots, \mathbf{y}_{i T}^{\prime}\right)^{\prime}$, given the history of exogenous variables (including bargaining factors $\mathbf{p}_{i t}$ for ease of notation) $\mathbf{z}_{i,-0}=$ $\left(\mathbf{z}_{i 1}^{\prime}, \ldots, \mathbf{z}_{i T}^{\prime}\right)^{\prime}$, household types $\mathbf{k}_{i}=\left(\mathbf{k}_{i 1}^{\prime}, \ldots, \mathbf{k}_{i T}^{\prime}\right)^{\prime}$, a specific value for $\boldsymbol{\alpha}_{i}$ and some initial condition $\mathbf{y}_{i, 0}^{*}$, is (we suppress the parameters for now):

$$
\operatorname{Pr}\left(\mathbf{y}_{i,-0} \mid \mathbf{z}_{i,-0}, \mathbf{k}_{i}, \boldsymbol{\alpha}_{i}, \mathbf{y}_{i, 0}^{*}\right)=\prod_{t=1}^{T} \operatorname{Pr}\left(\mathbf{y}_{i t} \mid \mathbf{z}_{i t}, \mathbf{k}_{i t}, \boldsymbol{\alpha}_{i}, \mathbf{y}_{i, 0}^{*}\right),
$$

which follows from the time-independence assumption on $\varepsilon_{s i t}$. If the $\varepsilon_{\text {sit }}$ follow a GEV(1) distribution, then we have the familiar conditional logit formulation

$$
\operatorname{Pr}\left(d_{i t}^{s}=1 \mid \mathbf{z}_{i t}, \mathbf{k}_{i t}, \boldsymbol{\alpha}_{i}, \mathbf{y}_{i, 0}^{*}\right)=\frac{\exp \left(u_{*}^{h}\left(\mathbf{y}_{i t}^{s}, \mathbf{k}_{i t} ; \mathbf{z}_{i t}\right)\right)}{\sum_{s^{\prime}} \exp \left(u_{*}^{h}\left(\mathbf{y}_{i t}^{s}, \mathbf{k}_{i t} ; \mathbf{z}_{i t}\right)\right)},
$$

where $d_{i t}^{s}$ is an indicator variable that equals 1 if choice $\mathbf{y}_{i t}^{s} \in B\left(r_{i t-1}^{m}, r_{i t-1}^{f}, t\right)$ is observed and $s^{\prime}$ denotes the available choices.

For a well-defined likelihood we need to take the expectation of this probability with respect to the joint probability distribution of the unobserved heterogeneity and the initial condition $\mathbf{y}_{i, 0}^{*}$. One cannot plausibly assume that $\boldsymbol{\alpha}_{i}$ is independent of $\mathbf{y}_{i, 0}^{*}$ such that we need to specify further our parametric model (Heckman, 1981). In the present context, Wooldridge (2002) suggested that postulating a conditional distribution for $\operatorname{Pr}\left(\mathbf{y}_{i, 0}^{*} \mid \boldsymbol{\alpha}_{i}\right)$ is not less restrictive than imposing one for $\operatorname{Pr}\left(\boldsymbol{\alpha}_{i} \mid \mathbf{y}_{i, 0}^{*}\right)$. Therefore we make the assumption that $\boldsymbol{\alpha}_{i}$ arises from a linear projection on a vector of initial conditions, $\mathbf{y}_{i, 0}^{j *}=\left(l_{i 0}^{m}, l_{i 0}^{f}, h s_{i 0}^{j}\right)^{\prime}$ with $h s_{i 0}^{j}$ being the initial health status of spouse $j: \pi_{j}^{\prime} \mathbf{y}_{i, 0}^{j *}$. Due to the conditioning on initial health, any remaining effect from other health variables will not come from the correlation in time-invariant unobservables that affect health and labor supply over the life-cycle (see Michaud and van Soest, 2004). 
For the estimation, we use maximum simulated likelihood. We have the following likelihood function that is to be maximized; where $\widetilde{\boldsymbol{\alpha}}_{i r}$ are draws from $N_{2}\left(0, \Omega_{\alpha}\right)$ :

$$
\max _{\boldsymbol{\theta}} \sum_{i=1}^{N} \log \frac{1}{R} \sum_{r=1}^{R} \prod_{t=1}^{T} \operatorname{Pr}\left(d_{i t}^{s}=1 \mid \mathbf{z}_{i t}, \mathbf{k}_{i t}, \widetilde{\boldsymbol{\alpha}}_{i r}, \mathbf{y}_{i, 0}^{*} ; \boldsymbol{\theta}\right)
$$

where $\boldsymbol{\theta}$ denotes the parameters to estimate.

The estimator is consistent for $N$ and $R$ going to infinity and asymptotically equivalent to maximum likelihood for $R / \sqrt{N}$ tending to infinity (Hajivassiliou et al., 1996). As it turns out in the empirical exercise, conditioning on initial hours choices and initial health in the coefficient associated to own leisure is enough to capture the latent correlation across periods in choices (i.e., the variances of unobserved heterogeneity go to zero). Note that this does not imply that unobserved heterogeneity is not present. It is shown in Wooldridge (2002), though, that if it is present, then conditioning on initial choices provides consistent estimates. Naturally, this greatly simplifies the computation problem and therefore we do not need to conduct Monte Carlo integration for each sequence of decisions.

\section{Data}

We apply our model to data that are drawn from the Health and Retirement Study (HRS). The HRS is sponsored by the National Institute on Aging and conducted by the University of Michigan. It consists of a longitudinal study following a cohort of individuals who were born between 1931 and 1941 (both years included), and their spouses if married (regardless of age). The HRS is extremely rich and encompasses lots of socio-economic information like the respondents' demographic background, employment status, job history, income sources, health status, wealth and pension plans. Moreover, the HRS includes a linkage with administrative data of the Social Security Administration which provides respondents' earnings histories from 1950 to 1991, allowing an accurate calculation of the Old Age Social Insurance benefits. We use the public release (version C) of the HRS from the RAND Corporation (StClair et al., 2002), which merges respondents from the five available biennial waves covering the period between 1992 and 2000. These data are complemented with the SSA files and the employer-provided pension information.

The sample selection is for married or cohabiting couples where both individuals were alive in 1992. For identification reasons explained earlier, these initial couples remain in the dataset for the five waves, irrespective of the fact that some individuals turn to widow(er)hood in the given time span. After deleting observations with important missing information, we have a sample of 2,495 households that are observed in five consecutive periods. ${ }^{7}$

\footnotetext{
${ }^{7}$ Since we need accurately calculated OASI benefits, the sample selection was for respondents who gave permission to link their earnings histories as reported to the Social Security Administration to the HRS. Earnings
} 
Table 1 reports, across all-waves, the numbers of complete couples, widows and widowers along with summary statistics of key variables in the analysis. As is clear from the table, and according to common knowledge, more widows than widowers are observed as time proceeds. Widows and widowers are generally in worse health than their counterparts in couples. This may reflect some correlation with their lost spouse's health (see Michaud and van Soest, 2004), but may also be due to the fact that individuals in couples are older on average than widow(er)s. Note that about 7 to $10 \%$ of the spouses experienced a severe health onset (e.g., cancer, a heart condition or a stroke) during the survey. The table further indicates that about one fifth of the sample had been subject to a severe health onset before participation to the survey. This is the case for more than half of the sample as far as mild health onsets (e.g., diabetes, arthritis or mental problems) are concerned. Focusing on labor supply, it turns out that widowers work less than males in couples, which is the case for both the extensive and the intensive margin. For widows, this is only the case with respect to the choice between working or not working. The table also indicates that widow(er)s generally earn less than individuals in couples, and that they have lower pension income and social security benefits. On the other hand, substantially more widow(er)s claimed OASI-benefits. Worthy of note from our model's point of view is that about a quarter of the individuals want to retire at the same time as their spouse.

[Table 1 about here]

Many features of the HRS data with respect to retirement behavior have already been thoroughly discussed. Especially the extensive margin (working versus being retired) attracted much attention in the literature (see, e.g., Coile and Gruber, 2000, Maestas, 2001, Gustman and Steinmeier, 2002, and Michaud, 2003). Given our model's set-up, we will focus on both the extensive and the intensive margin of labor supply behavior of the elderly in what follows; a feature of the HRS data that has not been widely dealt with. In addition, we pay ample attention to the claiming decision for social security benefits.

In the top panel of Table 2, ages are shown when individuals started claiming social security benefits (for the year 2000). It is clear from the table that most spouses start claiming at the age of 62 , which reflects the rather low accruals that one gets by delaying the claim for benefits. Of course, quite some individuals claim when they are older. Possible reasons may be earnings replacement, heterogenous preferences or spousal considerations. The bottom panel of the figure shows the distribution of the difference in claiming age for those who claimed conditional on the husband's claiming age. As has already been noticed by Maestas (2001), more than one third of the claimants do it within one year of each other. Interestingly, this frequency is highest when the husband claimed at the age of 65 . Taking into account an average

histories are available for about $75 \%$ of the HRS respondents. According to Haider and Solon (2000), the HRS Social Security earnings sample is reasonably representative for the original sample. 
age difference of three years, this implies that wives start claiming at the age of 62 . A clear candidate for why this pattern emerges is the spouse allowance.

[Table 2 about here]

Table 3 gives couples' labor supply choices for each of the four possible combinations of the spouses' claiming decision. It is clear from the tables that there are quite important numbers of households in almost all combinations of hours choices. This indicates that it is indeed worthwhile to also look at the intensive margin when dealing with retirement behavior. Further, although the claiming of social security benefits is associated with a higher percentage of non-participation of the claimants, it is not the case that the latter always quit the labor market once this decision has been taken: a high number of claimants keep on working. Since this is mainly part-time, there are indications that the earnings test influences this pattern. It is also noticeable that the percentages of non-claiming individuals who do not participate or who work part-time are higher if these non-claimants are married with a claiming spouse. We also checked possible correlations between the spouses' labor supply choices across all possible claiming configurations. A Chi-square test of independence strongly rejects the null hypothesis of independent choices. A similar exercise has been done with respect to the spouses' labor supply transitions. Once again, a Chi-square independence test strongly rejects the hypothesis that spouses change labor supply independently from each other, which implies that it is worth considering externalities in leisure when modelling couples' labor supply behavior.

[Table 3 about here]

In Table 4, we concentrate on the possible correlation between the claiming decision and the hours of work decision. More specifically, transition matrices for hours of work are computed for spouses who did not claim in the initial period, compared to those who either claimed or still have not claimed benefits in the next period. Interestingly, claiming spouses tend to move from non-participation and full-time work (30-50 hours per week) to part-time work (1-30 hours per week) to a greater extent, than their non-claiming counterparts. For example, of those husbands who did not claim in the initial period, $25 \%$ claimed social security benefits and went to part-time work in the next period. This is the case for only $6 \%$ of those husbands who did not claim in the next period. For wives, a similar pattern emerges.

[Table 4 about here] 
Let us finally have a look at some budget sets. ${ }^{8}$ In Figures 1 and 2, we show budget sets for households with respectively a 67 years old husband and a husband that has age 62 in 2000, and who both are eligible for Old Age Social Insurance. The upper-left panel in each figure gives the budget set for a household where both spouses have an hourly wage rate that is equal to the 25 th quantile of the male and female wage distributions. This boils down to an hourly wage of 12.71 USD for males and 9.01 USD for females. We assume that the household has a non-labor income equal to the 25th quantile of the associated distribution, which is split between spouses for taxation purposes. Further, the Average Indexed Monthly Wage is respectively equal to 2430.20 and 654.20 USD for the husband and the wife. The bottom-left panel of each figure shows a similar budget set where wages and non-labor incomes are equal to the 75th quantile of the respective distributions. Male and female wages are here equal to 24.74 and 16.65 USD, while the non-labor income equals 14,000 USD. The AIME is equal to 3941.10 USD for the husband and 1818.60 USD for the wife. All left-hand side graphs thus show how household consumption increases if either the husband or the wife, or both of them, increase their labor supply.

The two-dimensional right-hand side panels of the figures show the budget set of the husband conditional on the number of hours worked by his wife (i.e., the lowest curve corresponds to non-participation of the female, while the highest curve is associated with a labor supply of 60 hours).

It is clear from the different panels in Figure 1 that the budget sets are convex and have everywhere a relatively constant slope for both household types with a 67 year old husband. Social security and progressive income taxation do not introduce very important non-linearities (kinks) and non-convexities into the budget set for these households. Another picture emerges for couples with a husband that has age 62 (Figure 2). Here, the budget set has some pronounced inward kinks and an outward kink that makes the budget set non-convex. Marginal tax rates are thus higher once the inward kink is passed, while they are decreased at a higher amount of hours (the exact kink of course differs for low and high earners). The main reason for the different picture in the two figures is the earnings test that has different consequences depending on the age of the husband. First of all, the threshold level differs for husbands below or above the normal retirement age; thus introducing a different inward kink in the budget set. Further, for the younger household, the earnings test introduces a tax of $50 \%$ on the benefits, once its threshold is passed. The steeper slope at high working hours is due to the fact that all benefits are taxed away, and the usual marginal income tax rate applies. Benefits of the household with a husband of 67 years old are only taxed at $33 \%$. This rate is closer to the marginal income tax rate of the bulk of the households, which explains the hyperplane-like budget set.

To conclude, it is clear that incentives are highly different for households that differ along

\footnotetext{
${ }^{8}$ These budget sets are based on the observed wages and do not take account of accruals.
} 
the age and income dimensions. Due to the complexity of our model (each spouse has own preferences, while there is bargaining within the household), it is rather difficult to make a priori statements on how these incentives will affect labor supply behavior (compare to Moffitt, 2003). Empirical estimates and simulations will be able to shed light on the issue. Note also that the budget sets shown illustrate the usefulness of our discrete choice approach, which is very convenient to deal with non-convexities and non-linearities.

[Figure 1 about here]

[Figure 2 about here]

\section{Empirical results}

We applied the empirical model described above under the assumption that each spouse has four labor supply choices. These options range from nonparticipation to working on average 60 hours per week, in steps of 20 hours. Taken together, this implies that each couple is confronted with 16 labor supply options. Model estimates are shown in Table 5. Once initial conditions are taken into account, it turns out that no unobserved heterogeneity is left in individual preferences. Parameter estimates are therefore those with unobserved heterogeneity parameters $\alpha_{i}^{j}$ set equal to zero $(j=m, f ; \forall i)$.

Let us first have a closer look at the preference parameters. Focusing on health, the number of onsets of severe diseases like cancer, a heart condition or a stroke, seems to have a positive and significant impact on the parameters $\beta_{j}^{j}(j=m, f)$, which are associated with a spouse's own leisure. Since this variable is insignificantly estimated in the marginal utility of consumption $\beta_{c}^{j}(j=m, f)$, one may conclude that severe health onsets have a negative impact on hours worked, which is of course quite intuitive. Since these onsets appear in several places in the econometric specification, it may be hard to interpret their impact. Therefore, we calculated the increase in the marginal rate of substitution between leisure and consumption due to the parameters associated with a severe onset (see Table 6). It turns out that a severe onset with respect to the husband is equivalent to having to compensate between 5.17 and 19.9 dollar per hour more. Since marginal rates of substitution are already quite high, this implies that it is even less plausible that a husband will keep on working after such an onset. Onsets of mild diseases like arthritis and diabetes have only a significant impact on male labor supply. This seems to support the case that one can still work for some time after an onset of a mild disease. Note, however, that the initial health condition captures a lot of the propensity to get such disease, implying that its effect may already be captured elsewhere. Restrictions in activities of daily living (ADLs; bathing, eating, walking across a room, getting in or out of bed, etc.) influence labor supply behavior of the spouse. Estimated parameters with respect to ADLs have an opposite impact on preferences though. According to the associated results in Table 6 , 
however, one may conclude that their impact on hours worked is strongly negative. Note that the huge impact in the 95th percentile can be explained by the linear effect of restrictions in ADLs. If someone has a partner who cannot get out of bed alone, cannot eat alone, etc., then this surely has its consequences on his or her labor supply. Note that since we conditioned on initial health, it can be argued that health has a causal effect on hours worked (see also Michaud and van Soest, 2004). Taken as a whole, the effect of the different health indicators on preferences accords with intuition: a bad health has a negative impact on labor supply. Since several measures have a significant and different impact on spouses' labor supply, the results illustrate that health is multidimensional and that different measures have their place in a labor supply model.

A second group of variables that have an important and significant impact on preferences are the dummies indicating how many hours an individual worked in the last period. The results indicate that, ceteris paribus, a higher number of hours worked in the former period results in a higher labor supply in the current period. As mentioned earlier, this may point to the presence of habit formation or hours restrictions due to, for example, fixed costs of participation. Also initial own leisure is significant, which stresses the importance of initial conditions to account for unobserved preference heterogeneity. Note, however, that the partner's initial leisure is not significant. This is probably due to the fact that we already conditioned on the partner's restrictions in ADLs: if a partner suffered from such restrictions initially, then it is plausible that she or he did not work in later periods.

We can also see from Table 5 that there are significant externalities with respect to leisure in couples. This is the case for both the parameters $\beta_{j^{\prime}}^{j}$ and the parameters $\beta_{m f}^{j}(j=m, f)$. The impact of a subjective indicator for a preference for shared leisure is in line with results obtained by Maestas (2001), Gustman and Steinmeier (2002) and Coile (2003). One puzzling result is obtained when the total marginal effect of spousal leisure is calculated: for men, it is positive, while there are, on average, (rather small) negative externalities for women.

A major feature of our model is that it is embedded in the collective approach to household behavior. As the results in the bottom part of Table 5 indicate, this structural aspect cannot be ignored. First of all, the husband's wage rate has a positive and highly significant impact on his utility weight, which itself has consequences on how leisure and consumption is allocated within the household. Remark that this does not necessarily imply that his leisure will increase at the cost of decreasing the amount of leisure of his spouse, all other things equal. The exact allocation of course depends on the valuation of the different commodities in the utility function. Secondly, and according to intuition, the female's wage has a negative effect on the husband's utility weight; the latter is not significant though. Also the household's nonlabor income has a negative and significant impact on the husband's bargaining weight. Remark that these results imply a strong rejection of the standard unitary model, which is characterized by price-independent utility functions. Simulations obtained by means of models not taking into 
account intrahousehold bargaining aspects should thus be interpreted with care. Also some specific aspects of the social security system influence a household's bargaining process. This is the case for the husband's AIME, which has a negative impact on his weight. One explanation for this effect is that if a husband has a high AIME, then his spouse can collect a high spouse benefit or a divorce benefit whatever the husband does. The returns from the spouse benefit accrue to her, independently of her participation status, which may increase her bargaining position.

[Table 5 about here]

[Table 6 about here]

The model's fit is illustrated in Table 7. The table shows observed and predicted couples' labor supply frequencies for the year 2000. The predicted frequencies will serve as the baseline situation in the simulation exercise. It is clear from the table that the number of couples where both spouses do not participate is well predicted. On the other hand, the cell where both spouses work on average 40 hours per week is underpredicted. Although a chi-square goodness-of-fit test rejects the null-hypothesis that the predicted frequencies come from the same distribution as the observed ones, it is quite satisfactory that the model allocates couples to all possible choices. This stresses that it is worthwhile focusing on the intensive margin, on top of the discrete choice between working and not working.

[Table 7 about here]

\section{Simulations}

\subsection{Social security reforms}

We now discuss simulation results by means of the above identified model. Several proposals to increase labor force participation of the elderly have been made by policy makers. In this section, we discuss two such proposals.

The first simulation that we focus on is the elimination of the spouse benefit or spouse allowance. According to current Social Security rules, a spouse is entitled to the maximum of the own benefit and half of the Primary Insurance Amount of the other spouse, given that he or she is eligible for Old Age Social Insurance benefits, to which own actuarial adjustments are imposed (see Appendix A). It is clear that this rule may have an impact on labor supply decisions of the individuals in married couples. Blau (1997), for example, concludes that the elimination of the spouse allowance and its replacement by a system of earnings sharing decreases husbands' participation rates, while there is a positive impact for married women. 
The second proposal is the abolition of the earnings test. Currently, Old Age Social Insurance benefits are reduced if one has a labor income above some threshold if one is younger than the normal retirement age. Up to 2000, this was also the case for beneficiaries older than the normal retirement age. ${ }^{9}$ In order to study possible disincentive effects of this rule, we simulate the complete removal of the earnings test for both beneficiaries below and above the normal retirement age. Earlier results in the literature gave a rather diffuse picture of the labor supply effects of the earnings test. Reimers and Honig (1996), for example, conclude that women are not affected by the earnings test, while there is some evidence that men are deterred from working by this rule. Friedberg (2000) comes to similar results for older men. Gruber and Orszag (2000), on the contrary, claim that there is no robust influence on the labor supply of men, while there is some evidence that the earnings test has an impact on the labor supply decisions of women.

\subsection{Results}

As mentioned when we discussed the model's fit, predicted frequencies for married couples in the year 2000 are the baseline situation in the simulation exercise. Starting from this baseline, we proceed discussing the impact of the social security reforms on hours worked. Changes in the relative frequencies of couples' labor supply choices are given in Table 8. As is clear from the table, the impact of both reforms is rather marginal. Worthy of note with respect to the abolition of the spouse allowance is that it has a positive impact on female labor supply, which points to disincentive effects associated with the allowance. This result confirms earlier results obtained by Blau (1997). The impact of the abolition of the earnings test is relatively more important than the spouse allowance reform, although its effect must not be overestimated. ${ }^{10}$ The reform implies a decrease in the relative frequency of couples where both spouses are not participating. Quite intuitively, this is coupled to an increase in the labor supply of husbands; although also some wives increase their labor supply after the abolition of the earnings test. Note that these different changes point out that labor supply dynamics go beyond the choice between participation and non-participation; also the intensive margin is important. We can conclude from these simulation results that the abolition of the earnings test has a positive, though small, impact on the labor supply of men, while the effect on women's labor supply is less obvious. These results thus seem to confirm earlier results obtained by Reimers and

\footnotetext{
${ }^{9}$ The 'Senior Citizens Freedom to Work Act' of 2000 abolished the earnings test for those over the Social Security normal retirement age. Given the timing of our data, we did not take into account this Act to estimate the model. As a result, simulations may underestimate the effect of the removal of the earnings test, since individuals may have anticipated the Act. Note also that the loss in benefits due to the earnings test are paid at a later age when earnings are below the cap. In our myopic model, though, individuals consider these benefit reductions as pure losses.

${ }^{10}$ Note that the estimated effect of the abolition of the earnings test will be an overestimate of the true effect, since our myopic model does not take into account that benefit losses due to the test are not pure income losses in reality (see also Appendix A).
} 
Honig (1996) and Friedberg (2000) by means of reduced form models.

[Table 8 about here]

Our model also allows to analyze the impact of the social security reforms on the claiming decision, which is reported in Table 9. Once again, the reforms' impact is rather marginal. The abolition of the spouse benefit implies that some women, who have a claiming husband, start claiming after the reform. Easier to rationalize is the impact of the elimination of the earnings test on the claiming decision. This reform implies a higher number of individuals (both men and women) who start claiming benefits after the reform. Of course, this is due to the fact that one can keep on working many hours without losing part of the social security benefits.

[Table 9 about here]

A final result worth mentioning is the comparison of the impact on hours worked for the situation where the husband claimed, while the wife did not claim social security benefits. This exercise's results are shown in Table 10. In this particular situation, the abolition of the spouse allowance is coupled with a higher labor supply of females. This can be explained by the fact that women cannot rely any longer on their husband's benefit in future, and that it is thus worthwhile to increase their own future benefits by working more. The impact of the elimination of the earnings test is similar, but somewhat more pronounced, to that obtained for the whole sample. Once again, this is mainly due to the disincentive effects (especially for men) associated with the earnings test.

[Table 10 about here]

\section{Conclusion}

We presented a structural model to study labor supply behavior of elderly households. Specific to the model is that it is embedded in the collective approach to household behavior. By doing this, we explicitly take into account that spouses may have different preferences over leisure and consumption and that bargaining is involved to reach observed household allocations, which are assumed to be Pareto efficient. Since preferences allow for general externalities with respect to leisure, our model is able to deal with the widely observed coordinated retirement decisions between spouses. We further do not only focus on the extensive margin (working versus being retired), but also on the intensive margin (how many hours are worked). Moreover, also the 
claiming decision for social security benefits is incorporated in the model. Preferences and the intrahousehold bargaining process are identified by making use of panel data with couples and individuals who turned into widow(er)hood in the covered period, along with the assumption that preferences do not change (except for possible health shocks), in such an event.

We applied our model to a sample of US households coming from the first five waves of the Health and Retirement Study. Many of the model's parameters were significantly estimated and had implications that were according to intuition. Health effects are important. Moreover, they illustrate that health is multidimensional and that different measures of health all have their place in a labor supply model. We further found strong dependence on past labor supply behavior, which may point to habit formation or hours restrictions due to fixed costs to participation. Important from the model's point of view is that the spouses' weights in the intrahousehold allocation process significantly depend on their wages. This implies a rejection of the standard unitary model, where household preferences are price-independent.

Finally, we conducted simulations of two widely discussed social security reforms by means of our structural model. The first exercise consisted of the abolition of the spouse benefit. This reform has almost no impact on spouses' labor supply behavior, although there are indications that there are disincentive effects associated with the spouse allowance. The second reform concerned the abolition of the earnings test. It turned out that there is a small positive impact on male labor supply, while the effect on women's participation is rather unimportant.

All results taken as a whole, the tentative conclusion can be drawn that health effects and state dependence are much more important to explain observed labor supply behavior of the elderly, than social security features as the earnings test or the spouse allowance. As a consequence, major increases in male and female participation rates seem only possible for more sweeping social security reforms than the currently discussed ones.

A potential critique is that our model essentially implies that individuals in couples are myopic; any future value from their actions is not considered in the household decision-making process (apart from taking into account the implicit social security tax). A dynamic programming approach would be feasible and we intend to follow that line in future research (see Rust et al., 2001, Blau and Gilleskie, 2001, and van der Klaauw and Wolpin, 2003, for such attempts). Indeed, this would allow dealing more accurately with forward-looking aspects concerning the earnings test.

\section{References}

[1] Blau, D. (1997), "Social security and the labor supply of older married couples", Labour Economics, 4, 373-418.

[2] Blau, D. (1998), "Labor force dynamics of older married couples", Journal of Labor Economics, 16, 595-629. 
[3] Blau, D. and D. Gilleskie (2001), "Health insurance and retirement of married couples", mimeo, University of North Carolina.

[4] Bourguignon, F. and P.-A. Chiappori (1994), "The collective approach to household behavior" in R. Blundell, I. Preston and I. Walker (eds.), The Measurement of Household Welfare, Cambridge, Cambridge University Press, 70-85.

[5] Browning, M. and P.-A. Chiappori (1998), "Efficient intra-household allocations: a general characterization and empirical tests", Econometrica, 66, 1241-1278.

[6] Cherchye, L. and F. Vermeulen (2003), "Nonparametric analysis of household labour supply: goodness-of-fit and power of the unitary and the collective model", CES-Discussion Paper 03.02, Center for Economic Studies, Leuven.

[7] Chiappori, P.-A. (1988), "Rational household labor supply", Econometrica, 56, 63-89.

[8] Chiappori, P.-A. (1992), "Collective labor supply and welfare", Journal of Political Economy, 100, 437-467.

[9] Chiappori, P.-A. and I. Ekeland (2002), "The micro economics of group behavior: identification", mimeo, Chicago, University of Chicago.

[10] Chiappori, P.-A., B. Fortin and G. Lacroix (2002), "Marriage market, divorce legislation and household labor supply", Journal of Political Economy, 110, 37-72.

[11] Coile, C. (2003), "Retirement incentives and couples' retirement decisions", NBER working paper 9496, Cambridge MA.

[12] Coile, C. and J. Gruber (2000), "Social security incentives for retirement", NBER working paper 7651, Cambridge MA.

[13] Coile, C., P. Diamond, J. Gruber and A. Jousten (2003), "Delays in claiming social security benefits", forthcoming in Journal of Public Economics.

[14] Fortin, B. and G. Lacroix (1997), "A test of the unitary and collective models of household labour supply", Economic Journal, 107, 933-955.

[15] Friedberg, L. (2000), "The labor supply effects of the social security earnings test", Review of Economics and Statistics, 82, 48-63.

[16] Gruber, J. and P. Orszag (2000), "Does the social security earnings test affect labor supply and benefit receipt", working paper Center for Retirement Research at Boston College, Chestnut Hill, Ma.

[17] Gruber, J. and D. Wise (eds., 1999), Social Security and Retirement around the World, Chicago, University of Chicago Press. 
[18] Gruber, J. and D. Wise (2002), "Social security programs and retirement around the world: micro estimation", NBER working paper 9407, Cambridge MA.

[19] Gustman, A. and T. Steinmeier (1986), "A structural retirement model", Econometrica, $54,555-584$.

[20] Gustman, A. and T. Steinmeier (2000), "Retirement in dual-career families: a structural model", Journal of Labor Economics, 18, 503-545.

[21] Gustman, A. and T. Steinmeier (2002), "Social security, pensions and retirement behavior within the family", NBER working paper 8772, Cambridge MA.

[22] Gustman, A. and T. Steinmeier (2004), "Personal Accounts and Family Retirement", Michigan Center for Study on Aging, Ann Arbor Michigan.

[23] Haider, S. and G. Solon (2000), "Nonrandom selection in the HRS social security earnings sample, RAND working paper DRU-2254-NIA, Santa Monica.

[24] Hajivassiliou, V., D. McFadden and P. Ruud (1996), "Simulation of multivariate normal rectangle probabilities and their derivatives: theoretical and computational results", Journal of Econometrics, 72, 85-134.

[25] Heckman, J. (1981), "The incidental parameters problem and the problem of initial condition in estimating a discrete-time data stochastic process", in C. Manski and D. McFadden (eds.), Structural Analysis of Discrete Data with Econometric Applications, Cambridge, MIT Press, 179-195.

[26] Heckman, J. and R. Willis (1977), "A beta-logistic model for the analysis of sequential labor force participation by married women", Journal of Political Economy, 85, 27-58.

[27] Health and Retirement Study (2003), (Waves 1-5/Years 1992-2000) public use dataset. Produced and distributed by the University of Michigan with funding from the National Institute on Aging. Ann Arbor, MI.

[28] Hurd, M. (1996), "The effects of labor market rigidities on the labor force behavior of older workers", in D. Wise (editor), Advances in the Economics of Aging, Chicago University Press, 11-58.

[29] Hurd, M., L. Lillard and C. Panis (1998), "An analysis of the choice to cash out pension rights at job change or retirement", RAND working paper DRU-1979-DOL, Santa Monica.

[30] Kooreman, P. and A. Kapteyn (1990), "On the empirical implementation of some game theoretic models of household labor supply", Journal of Human Resources, 25, 584-598.

[31] Lazear, E. (1986), "Retirement from the labor force", in O. Ashenfelter and R. Layard (eds.), Handbook of Labor Economics, Vol. 1, Elsevier Science, 305-355. 
[32] Lumsdaine, R. and O. Mitchell (1999), "New developments in the economic analysis of retirement", in O. Ashenfelter and D. Card (eds.), Handbook of Labor Economics, Vol. 3, Elsevier Science, 3261-3307.

[33] Maestas, N. (2001), "Labor, love and leisure: complementarity and the timing of retirement by working couples", mimeo, Department of Economics, UC Berkeley.

[34] Mastrogiacomo, M., R. Alessie and M. Lindeboom (2002), "Retirement behaviour of Dutch elderly households", forthcoming in Journal of Applied Econometrics.

[35] Mazzocco, M. (2001), "Household intertemporal behavior: a collective characterization and empirical tests", Mimeo, Madison, University of Wisconsin.

[36] Michaud, P.-C. (2003), "Joint labour supply dynamics of older couples", CentER Discussion Paper 2003-69, Tilburg, CentER.

[37] Michaud, P.-C. and A. van Soest (2004), "Health and wealth of elderly couples: causality using dynamic panel data models", Mimeo, Tilburg, CentER.

[38] Moffitt, R. (2003), "The negative income tax and the evolution of the U.S. welfare policy", Journal of Economic Perspectives, 17, 119-140.

[39] Reimers, C. and M. Honig (1996), "Responses to social security by men and women. Myopic and far-sighted behavior", Journal of Human Resources, 31, 359-382.

[40] Rust, J., M. Buchinsky and H. Benitez-Silva (2001), "An empirical model of social insurance at the end of the life cycle", mimeo, University of Maryland.

[41] Rust, J. and C. Phelan (1997), "How social security and medicare affect retirement behavior in a world of incomplete markets", Econometrica, 65, 781-831.

[42] Social Security Administration (2001), Social Security Handbook, http://www.ssa.gov/OP-home/handbook/ssa-hbk.htm.

[43] Social Security Administration (2003), Fast Facts and Figures about Social Security, SSA Publication 13-11785, Washington, SSA.

[44] StClair, P., D. Bugliari, P. Pantoja, S. Ilchuk, G. Lopez, S. Haider, M. Hurd, D. Loughran, C. Panis, M. Reti and J. Zissimopoulos (2002), RAND HRS Data Documentation, RAND Corporation, Santa Monica.

[45] Stock, J. and D. Wise (1990), "Pensions, the option value of work and retirement", Econometrica, 58, 1151-1180.

[46] Train, K. (2002), Discrete Choice Methods with Simulation, Cambridge, Cambridge University Press. 
[47] van der Klaauw, W. and K. Wolpin (2003), "Social security, pensions and the savings and retirement behavior of households", mimeo, University of North Carolina.

[48] van Soest, A. (1995), "Structural models of family labor supply. A discrete choice approach", Journal of Human Resources, 30, 63-88.

[49] Vermeulen, F. (2002), "Collective household models: principles and main results", Journal of Economic Surveys, 16, 533-564.

[50] Vermeulen, F. (2004), "And the winner is... An empirical evaluation of unitary and collective labour supply models", forthcoming in Empirical Economics.

[51] Vermeulen, F., O. Bargain, M. Beblo, D. Beninger, R. Blundell, R. Carrasco, M.-C. Chiuri, F. Laisney, V. Lechene, M. Myck, N. Moreau and J. Ruiz-Castillo (2003), "Collective models of household labour supply with non-convex budget sets and non-participation: a calibration approach", mimeo, Mannheim, ZEW.

[52] Wooldridge, J. (2002), "Simple solutions to the initial conditions problem in dynamic, nonlinear panel data models with unobserved heterogeneity", forthcoming in Journal of Applied Econometrics.

[53] Wu, S. (2003), "The effects of health events on the economic status of married couples", Journal of Human Resources, 38, 219-230. 


\section{Appendix A: Computation of net income}

In order to compute $M_{i t}$, full net income, we need to specify the tax schedule $F()$, as well as the old-age security insurance function $b()$. In what follows, observed wages and income are gross of any deductions or taxation.

\section{Old Age Security Benefits (OASI)}

First, we construct the Old-Age Social Insurance (OASI) benefits since these are taxable under federal income tax. ${ }^{11}$ We use the Social Security Handbook (2003), as well as Coile and Gruber (2000), to model the rules in effect. In a very general way, the benefit of the household is given by

$$
b_{i t}=b\left(w_{i t}^{m} h_{i t}^{m}, w_{i t}^{f} h_{i t}^{f}, a i m e_{i t}^{m}, a i m e_{i t}^{f}, a_{i t}^{m}, a_{i t}^{f}, k_{i t}^{m}, k_{i t}^{f}\right) .
$$

In what follows we suppress the household index $i$. We denote an individual by $j$ and his spouse by $-j$. Denote age as $a_{t}^{j}$ and therefore the birth year is defined by $t-a_{t}^{j}$. Old-Age Security Insurance benefits of a couple will depend on the following elements:

1. Covered Earnings Base: The Average Indexed Monthly Earnings (AIME) of each spouse aime $_{t}^{j}$,

2. Progressive Adjustment: The Primary Insurance Amount (PIA) of each spouse, $p i a_{t}^{j}$;

3. Actuarial Adjustment: The actuarial reduction factor (ARF), the delayed retirement credit (DRC) and the cost-of-living adjustment (COLA) for the PIA computed at age 62 .

4. Survivor and Spouse Benefits: The Spouse Allowance (SA) of each spouse, $s a_{t}^{j}$, the survivor benefit $s u_{t}^{j}$ if $k_{i t}^{-j}=0$ and the benefit cap on household total of each account (HT) is applied.

5. Earnings Test: The Earning test on each spouse's monthly benefit is applied to obtain the total benefit of the household.

\section{Covered Earnings Base (AIME)}

The computation of a monthly benefit is based on past earnings. The average indexed monthly wage is based on the contribution years of the employee. An employee's contribution to the social security fund is $7.3 \%$ which is matched by his employer. Most of it, $5.3 \%$, goes to financing OASI, with the residual part to disability insurance (0.9\%) and Medicare $(1.45 \%)$.

\footnotetext{
${ }^{11}$ We thank Nicole Maestas for allowing us to use her codes to calculate OASI benefits and for answering our questions on the rules on numerous occasions. The program used was benchmarked against the ANYPIA program from the Social Security Administration.
} 
All except Medicare contributions are levied on annual earnings up to $\$ 72,600$ in 1999 . In the HRS 1992 data we observe the earnings history of individuals from to 1950 to $1991 .^{12}$ Furthermore, we observe quarters where the individual was considered as covered (most sectors of the economy are covered). These quarters of contribution are part of the eligibility criterion.

- Quarters of Coverage: An individual is qualified for OASI benefits based on his birthyear. He is totally insured if he accumulated quarters of coverage $q_{t}^{j}$ at least equal to the number of years elapsed between the year where he turned 21 and the year when he turned 62 and first entitled to receive OASI benefits. For individuals born before 1929, this is computed from 1950 to the year where they turn 62 so that they may have a smaller number of quarters needed. Denote this minimum number of quarters of coverage as $m_{j}$. Therefore we define eligibility as

$$
e_{t}^{j}=I\left(q_{t}^{j} \geq m_{j}\right) I\left(a_{t}^{j} \geq 62\right) .
$$

Since starting in 1994, we must update quarters of coverage based on employment in 1992, we use the following rule to update $q_{t}^{j}$,

$$
q_{t}^{j}=4 h_{t}^{j}+q_{t-1}^{j} .
$$

We defined claiming as the first period where the individual is observed not working at or after age 62. Define these dates as

$$
t_{c}^{j}=\min _{s}\left\{s: e_{s}^{j}=1, h_{s}^{j}=0\right\} .
$$

This would capture most of the claiming decisions although it will miss those who delay claiming and those who claim and continue to work.

- Computation Years: The number of computation years equals the number of calendar years (complete) between first year of eligibility (62) and age where the individual turned 21 (1950 or later) minus five years. For most spouses retiring after 1991, this number that we denote by $c p_{j}$ will be 35 . For those born before 1929, the number of computation years are further reduced by the number of years that fill the gap between their birthyear and 1929 .

- Indexation: The amount earned (up to the yearly maximum (imposed on SSA files but manually imposed from 1994 onwards) in any year $t-s$ is indexed up to year $t$ where we want to compute the average monthly wage by the following ratio

$$
\pi_{t-s}^{j}=\frac{\bar{w}_{r: a_{r}^{j}=60}}{\bar{w}_{t-s}} I\left(a_{t-s}^{j} \leq 60\right)+I\left(a_{t-s}^{j}>60\right)
$$

where $\bar{w}_{r: a_{r}^{j}=60}$ is the national average wage of the year $r$, two years prior to eligibility . If the individual is older than 60 for the year where earnings are to be indexed, then there is no indexation or earnings for those years $\left(\pi_{t-s}^{j}=1\right)$.

\footnotetext{
${ }^{12}$ Those who accepted to allow HRS to match their SSA records. About three quarters gave permission and Haider and Solon (2000) find that the sample who does not give permission appears not to be different from those who gave permission.
} 
Given a history of covered earnings $\left\{\widetilde{w}_{t-s}^{j}\right\}_{s=1}^{a_{t}^{j}-21}$ (including zeros for years where no contributions were made), indexed earnings are defined as $w_{t-s}^{j}=\pi_{t-s}^{j} \widetilde{w}_{t-s}^{j}$ for $s=1, \ldots, a_{t}^{j}-21$.

- Computation of the AIME: Define the set $W_{t}^{j}$ as the highest $c p_{j}$ indexed covered earnings from $\left\{w_{t-s}^{j}\right\}_{s=1}^{a_{t}^{j}-21}$. Then the AIME of individual $j$ in year $t$ is given by

$$
\operatorname{aime}_{t}^{j}=\frac{1}{12 c p_{j}} \sum_{s=1}^{a_{t}^{j}-21} I\left(w_{t-s}^{j} \in W_{t}^{j}\right) \times w_{t-s}^{j} .
$$

Note that the $\operatorname{aime}_{t}^{j}$ does not depend on the date when one claims benefit.

The average monthly wage at $t$ needs to be updated after a year, at $t+1$ if this year's earnings $w_{t}^{j} h_{t}^{j}$ qualify in the new set $W_{t+1}^{j}$. This will happen if $w_{t}^{j} h_{t}^{j}$ is greater than the minimal element in the set $W_{t}^{j}, w_{t, \min }^{j}=\min _{w}\left\{w \in W_{t}^{j}\right\}$. We update the AIME for 1994 to 2000 as long as the individual does not claim benefit $\left(t_{c} \geq t\right)$.

\section{Progressive Adjustment (PIA)}

The Primary Insurance amount (PIA) is deduced from the AIME by applying a progressive piece-wise linear transformation. This calls for bendpoints where the inflections occur as well as conversion rates on each segment.

- Bend Points: Bend points are increased each year depending on the average national wage to reflect the similar indexation of the AIME. The base year for the bendpoint is 1979 . The two bendpoints were $\$ 180$ and $\$ 1085$ at that time. Denote those by $b d_{\min , 1979}, b d_{\max , 1979}$ respectively. Then, the bendpoints at $t$ are defined as

$$
\begin{aligned}
b d_{j \min } & =\frac{\bar{w}_{s: a_{s}^{j}=60}}{\bar{w}_{1977}} b d_{\min , 1979} \\
b d_{j \max } & =\frac{\bar{w}_{t: a_{t}^{j}=60}}{\bar{w}_{1977}} b d_{\max , 1979} .
\end{aligned}
$$

Therefore there are bendpoints specific to each spouse.

- Conversion Rates: There are three conversion rates since there are two bend points. These are $0.9,0.32$ and 0.15 and did not change over the period.

Once bendpoints are calculated for a spouse (which does not depend on claiming date but on first-eligibility date), the PIA is given by

$$
\begin{aligned}
p i a_{t}^{j}= & 0.9 \min \left(a i m e_{t}^{j}, b d_{j \min }\right) \\
& +0.32 \min \left(\max \left(a i m e_{t}^{j}-b d_{j \min }, 0\right), b d_{j \max }-b d_{j \min }\right) \\
& +0.15 \max \left(a i m e_{t}^{j}-b d_{j \max }, 0\right) .
\end{aligned}
$$


Changes in the PIA will result from changes in the AIME. The relation is non-linear if the AIME crosses a bend point. A host of adjustments are imposed on this PIA depending on the claiming date.

\section{Actuarial Adjustments}

The normal retirement age $n r a_{j}$ is different for each individual and defined by the month and year of birth of $j$. It progressively increases from 65 to 67 over the period as a result of the 1983 amendments the Social Security Law. Since we model the annual budget set, there are only two normal retirement ages in the sample based on birthyear; 65 years old for individuals born before or in 1942 and 66 years old after. There are no individuals for which the normal retirement age is 67 in the sample.

If an eligible individual claims some year before age $n r a_{j}$, his monthly benefit calculated from the PIA is reduced by a factor

$$
a r f_{t}^{j}=\exp \left(-a r_{j} \max \left(n r a_{j}-a_{t}^{j}, 0\right)\right) .
$$

where $a r_{j}$ is a factor ( 0.687 for most individuals) which depends on the birthyear.

Similarly if a spouse claims after $n r a_{j}$ then there is a delayed retirement credit given by

$$
d r c_{t}^{j}=\exp \left(d r_{j} \max \left(a_{t}^{j}-n r a_{j}, 0\right)\right)
$$

where $d r_{j}$ is the delayed retirement credit factor which depends on birthyear.

There is also a cost-of living adjustment which is a function of the claiming date and of birthyear applied since the PIA bend points depended on virtual claiming age 62 instead of the actual claiming date. We apply the cola $a_{j}^{t}$ (cost-of-living adjustment for individual $j$ at time $t$ ) to any PIA after the claiming date.

Denote as $r_{t}^{j}$ the combination of all reduction factors if one claims at $t$,

$$
r_{t}^{j}=e_{t}^{j} \times a r f_{t}^{j} \times d r c_{t}^{j}
$$

Once an individual claims in the data we let $r_{t}^{j}=r_{t_{c}}^{j}$. However, the cola $a_{j}^{t}$ are applied to the PIA after the claiming date.

\section{Single and Couple and Survivor Monthly Benefit}

We first compute monthly benefits of each spouse not considering that there exists a spouse benefit. These are given by $b s_{t_{c}}^{j}$ defined as

$$
b s_{t_{c}}^{j}=r_{t_{c}}^{j} \times \operatorname{col} a_{t}^{j} \times p i a_{t}^{j}
$$

Note that the $p i a_{t}^{j}$ does not depend on the claiming date apart from the $a i m e_{t}^{j}$ which is not allowed to change once $t_{c}^{j} \leq t$. 
Spouse Benefit For the spouse benefit, denote the spouse of $j$ as $-j$. One is entitled for spouse benefits if the spouse has claimed benefits $\left(t_{c}^{-j} \leq t\right)$. Furthermore, the retiree needs to have a retiree benefit $b s_{t}^{j}$ which is smaller than half the spouse's PIA, pia $a_{t}^{-j}$ adjusted for one's own actuarial adjustments at $t, r_{t}^{j}$. Therefore the spouse benefit is denoted as $s b_{t}^{j}$ and given by

$$
s b_{t}^{j}=\max \left(I\left(t_{c}^{-j} \leq t\right)\left(0.5 r_{t}^{j} k_{t}^{-j} \operatorname{cola}_{t}^{j} p i a_{t}^{-j}-b s_{t}^{j}\right), 0\right) .
$$

Note that the individual's reduction factor and not that spouse's reduction factor, is applied to the spouse's PIA. In the household only one spouse can benefit from the spouse benefit as is clear from (23). ${ }^{13}$ Furthermore, note that the spouse benefit does not depend on the claiming date of the other spouse itself but on whether he/she claimed or not.

Survivor Benefit Finally we have to consider the survivor benefit if one of the spouses dies fully insured and the other spouse is over 62 years old. ${ }^{14}$ Then the survivor benefit is based on a comparison of the PIA of both spouse where the DRC's are applied to the deceased spouse's PIA. Therefore, the comparison for a widow $j$ is between $p i a_{t}^{j}$ and $d r c_{t}^{-j} p i a_{t}^{-j}$. Define $t_{d}^{j}$ to be the date at which an individual died. The survivor benefit is therefore given by

$$
s u_{t}^{j}=\max \left(\left(1-k_{t}^{-j}\right) r_{t}^{j} e_{t_{d}}^{-j} d r c_{t_{d}}^{-j} \operatorname{col}_{t}^{j} p i a_{t_{d}}^{-j}-b s_{t}^{j}, 0\right) .
$$

Since we do not model the children's budget set, we do not take account of child survivor benefit. Therefore, the survivor benefit is assumed to be only paid to the widow. On each retirement account there is a limit to family benefits. The benefit drawn on one account $\left(b s_{t}^{j}+s b_{t}^{-j}\right)$ cannot be in excess of $155-188 \%$ of the worker's PIA (depending on birthyear) (denote the rates $h c_{j}$ ). Since the household cap will in most cases be binding, we need to impose it on the total benefit of the household. However, we do not need to take account of the survivor benefit since it is only paid to one person and therefore cannot exceed the household cap. The household cap is binding if

$$
e x c_{t}^{j}=k_{t}^{-j} s b_{t}^{-j}+b s_{t}^{j}-h c_{j} p i a_{t}^{j}>0
$$

is greater than 0 . Finally, the benefit of a retiree $j$ (before the earnings test) is given by

$$
b e_{t}^{j}=k_{t}^{j} s b_{t}^{j}+b s_{t}^{j}-e x c_{t}^{-j} .
$$

\section{Earnings Test}

The earnings test is applied on the monthly benefit $b e_{t}^{j}$ differentially whether one is older or younger than the $n r a_{j} .{ }^{15}$ Earnings in year $t$ are given by $w_{t}^{j} h_{t}^{j}$ (only paid-work is counted

\footnotetext{
${ }^{13}$ We do not consider benefits allowed for divorced spouses and for other dependents in the household.

${ }^{14}$ Since we do not model disability insurance, we do not consider the possibility that a widow can collect survivor benefit prior to age 62 if on social security disability.

${ }^{15}$ In reality, benefit losses because of the earnings test are paid at a later age when earnings are observed below the cap. In our myopic model, agents interpret this as a pure loss in income and do not consider that it
} 
from employment or self-employment). The earnings test is based on an exemption amount

$e a_{t}^{j}$ which varies with $t$ and with the $n r a_{j}$ such that it depends on birthyear. If earnings are above that threshold $e a_{t}^{j}$, the benefits are taxed $50 \%$ if $a_{t}^{j}<n r a_{j}$ and $33 \%$ above or at the $n r a_{j}$. The tax rate function is therefore

$$
\operatorname{tax}_{t}^{j}=0.50-0.27 I\left(a_{t}^{j}>n r a_{j}\right)
$$

Finally, the final old age insurance benefit of a spouse is given by

$$
b_{t}^{j}=b e_{t}^{j}-\operatorname{tax}_{t}^{j} \max \left(w_{t}^{j} h_{t}^{j}-e a_{t}^{j}, 0\right) .
$$

Therefore the family benefit we are seeking is given by,

$$
b_{i t}=b_{t}^{m}+b_{t}^{f}
$$

In the budget set, we multiply this amount by 12 to get the annual income from benefits.

\section{Federal Tax Schedule: US Tax Code}

\section{Primitive concepts}

We describe a (very) simplified tax algorithm for a married couple with a joint return or for a surviving spouse. Note that other amounts than the discussed ones are applicable to unmarried singles or married individuals who file a separate return. Indices for observations and time are suppressed in what follows.

We start from two primitive concepts:

- annual earned income: $e i=\sum_{j} w^{j} h^{j}$

- annual gross income: sum of all incomes from whatever source: $g i=e i+y$.

\section{Social security contribution}

As indicated in the paper, employees contribute to social security via a charge on their earned income. Note that there is a cap on the contribution for OASI and disability insurance; this is not the case for Medicare. Therefore, we have:

- $s s c^{j}=(0.053+0.009) \times \min \left(72600, w^{j} h^{j}\right)+0.0145 \times w^{j} h^{j}$

- $s s c=\sum_{j} s s c^{j}$.

is only deferred to a later age. 


\section{Federal taxes}

From gross income to taxable income Taxable income equals gross income minus deductions. For simplification purposes, we will assume that individuals do not make use of itemized deductions. Therefore, deductions consist of standard deductions and the deduction for personal exemptions. We first have the standard deductions:

- basic standard deduction: $\$ 5000$;

- additional standard deduction for age: each spouse is entitled to an additional deduction of $\$ 600$ if the spouse has attained age 65 .

These deductions (starting from 1988) are subject to a cost-of-living adjustment. Then there is the allowance of deduction for personal exemptions:

- exemption amount: $\$ 2000$.

This exemption amount may be reduced if gross income exceeds the threshold amount $(\$ 150,000)$. Again, the exemption amount is adjusted for cost-of-living.

Assuming that no adjustments are made for cost-of-living, then the whole operation results in the following taxable income before application of the marginal tax rates schedule:

$$
t i=\max \left(g i-7000-600 I\left(a^{m} \geq 65\right)-600 I\left(a^{f} \geq 65\right), 0\right) .
$$

Marginal tax rates Married individuals who file joint returns and surviving spouses are subject to the following schedule of marginal tax rates:

[Table 11 about here]

Denote this function by $f$ and the amount of tax paid by $f(t i)$. The absolute amounts in this table are adjusted for inflation (starting from 1993).

Note that this scheme shows that one cannot apply the marginal tax rate on the whole taxable income to calculate tax liability. Only for couples that have a taxable income of at most $\$ 36,900$, the average and the marginal tax rates coincide.

\section{Credit for the elderly}

If individuals attain the age of 65 , they are eligible to a credit for the elderly. The credit is constructed as follows. First, there is an initial amount of $\$ 7500$ if both spouses are eligible (or $\$ 5000$ if only one spouse is eligible). This amount is reduced conditional on some factors. If gross income exceeds $\$ 10,000$, then the amount is reduced to one-half of the excess of the 
gross income over $\$ 10,000$. The final credit then equals $15 \%$ of the amount resulting from the operation of reducing the initial amount. So we have the following credit if both spouses are eligible:

$$
\text { cre }=\max [0,0.15 \times\{7500-0.5(g i-10000)\}]
$$

\section{Federal taxes to be paid}

Let us denote federal taxes to be paid by $f c$. These are given by subtracting $c r e$ from $f$.

\section{From gross to net}

Finally, net income (denoted by $M_{i t}$ ) is obtained by taking into account all appropriate elements (more specifically, gross income, social security contributions and federal taxes):

$$
M_{i t}=F()=g i_{i t}-s s c_{i t}-f c_{i t} .
$$


Table 1: Panel Composition and Main Caracteristics

\begin{tabular}{|c|c|c|c|c|}
\hline \multirow[t]{2}{*}{ Means/prop. reported } & \multicolumn{2}{|c|}{ alive in 2000} & \multicolumn{2}{|c|}{ died 1992-2000 } \\
\hline & husband & wife & widower & widow \\
\hline age & 60.8 & 56.9 & 63.1 & 62.44 \\
\hline \multicolumn{5}{|l|}{ Health } \\
\hline severe conditions ever & 0.194 & 0.153 & 0.231 & 0.188 \\
\hline severe conditions since & 0.074 & 0.056 & 0.100 & 0.061 \\
\hline mild conditions ever & 0.548 & 0.538 & 0.553 & 0.638 \\
\hline mild conditions since & 0.136 & 0.144 & 0.135 & 0.146 \\
\hline poor/very poor health & 0.189 & 0.173 & 0.286 & 0.212 \\
\hline adls (at least one) & 0.069 & 0.073 & 0.083 & 0.089 \\
\hline \multicolumn{5}{|l|}{ Labor market } \\
\hline working for pay & 0.640 & 0.540 & 0.532 & 0.486 \\
\hline claimed OASI & 0.305 & 0.160 & 0.440 & 0.253 \\
\hline hours worked (if $>0$ ) & 41.3 & 33.6 & 36.68 & 34.61 \\
\hline imp. hourly wage & 20.40 & 14.09 & 17.75 & 12.41 \\
\hline pension plan & 0.427 & 0.265 & 0.323 & 0.229 \\
\hline pension annuity 1992 & 12156 & 4224 & 10212 & 4283 \\
\hline AIME & 3058.8 & 939.9 & 2316.1 & 436.1 \\
\hline \multicolumn{5}{|l|}{ Couple preference } \\
\hline Pref. retire together & 0.265 & 0.231 & - & - \\
\hline Lenght of current mar. & \multicolumn{2}{|c|}{31.42} & - & - \\
\hline \multicolumn{5}{|l|}{ Total observations } \\
\hline 1992 & \multicolumn{2}{|c|}{2495} & - & - \\
\hline 1994 & \multicolumn{2}{|c|}{2446} & 8 & 41 \\
\hline 1996 & \multicolumn{2}{|c|}{2382} & 19 & 94 \\
\hline 1998 & \multicolumn{2}{|c|}{2294} & 34 & 164 \\
\hline 2000 & \multicolumn{2}{|c|}{2181} & 65 & 249 \\
\hline
\end{tabular}


Table 2: Social Security Claiming Decision

\begin{tabular}{l|cccccc}
\hline \hline & \multicolumn{7}{|c}{ Age start claiming (as of 2000) } \\
& not yet & 62 & 63 & 64 & 65 & $66+$ \\
\hline Husband & 45.77 & 33.15 & 5.89 & 3.77 & 7.58 & 3.56 \\
Wife & 62.16 & 27.66 & 4.65 & 1.48 & 2.65 & 1.2 \\
& \multicolumn{7}{|c}{ Age husb. starts claiming (as of 2000) } \\
\hline & Total & 62 & 63 & 64 & 65 & 66 \\
Ret. yr dif. & 46.88 & 52.8 & 55.7 & 45.6 & 25.4 & 22.2 \\
\hline-3 \&less & 11.02 & 12.3 & 6.8 & 8.8 & 7.9 & 16.7 \\
-2 & 12.85 & 12.9 & 11.4 & 11.8 & 14.9 & 11.1 \\
-1 & 15.67 & 11.9 & 18.2 & 17.7 & 25.4 & 27.8 \\
0 & 5.88 & 4.2 & 2.3 & 5.9 & 11.4 & 5.6 \\
1 & 2.94 & 1.5 & 2.3 & 7.4 & 6.1 & 8.3 \\
2 & 4.77 & 4.4 & 3.4 & 2.9 & 0.8 & 8.3 \\
3 \& more & 100 & 100 & 100 & 100 & 100 & 100 \\
\hline Total & \multicolumn{7}{c}{} & & & & & \\
\hline \hline
\end{tabular}


Table 3: Hours Worked per Week and Claiming Decisions

\begin{tabular}{|c|c|c|c|c|c|c|c|c|c|c|}
\hline \multirow[b]{2}{*}{ husb. } & \multicolumn{4}{|c|}{ wife (none claimed) } & \multirow[b]{2}{*}{ Total } & \multicolumn{4}{|c|}{ wife (wife claimed) } & \multirow[b]{2}{*}{ Total } \\
\hline & 0 & $1-30$ & $30-50$ & $50+$ & & 0 & $1-30$ & $30-50$ & $50+$ & \\
\hline 0 & 11.3 & 3.4 & 6.8 & 0.7 & 22.1 & 32.3 & 3.8 & 0.6 & 0 & 36.6 \\
\hline $1-30$ & 3.3 & 2.4 & 3.2 & 0.3 & 12.1 & 8.4 & 3.5 & 0.9 & 0.3 & 13.1 \\
\hline $30-50$ & 16.8 & 10.6 & 22.3 & 1.9 & 51.5 & 29.1 & 7.3 & 2.6 & 1.2 & 40.1 \\
\hline $50+$ & 5.4 & 3.5 & 7.0 & 1.4 & 17.3 & 7.0 & 2.3 & 0.9 & 0 & 10.2 \\
\hline \multirow[t]{2}{*}{ Total } & 36.8 & 19.9 & 39.2 & 4.2 & $65.8^{*}$ & 76.7 & 16.9 & 4.9 & 1.5 & $2.3^{*}$ \\
\hline & \multicolumn{4}{|c|}{ wife (husb claimed) } & & \multicolumn{5}{|c|}{ wife (both claim) } \\
\hline husb. & 0 & $1-30$ & $30-50$ & $50+$ & Total & 0 & $1-30$ & $30-50$ & $50+$ & Total \\
\hline 0 & 42.0 & 10.2 & 17.4 & 1.7 & 71.3 & 62.5 & 7.6 & 1.9 & 0.1 & 72.2 \\
\hline $1-30$ & 7.4 & 4.7 & 5.9 & 0.3 & 18.3 & 14.1 & 3.1 & 0.9 & 0.3 & 18.4 \\
\hline $30-50$ & 3.4 & 1.7 & 3.1 & 0.2 & 8.5 & 4.8 & 1.9 & 1.1 & 0.1 & 7.9 \\
\hline $50+$ & 0.6 & 0.6 & 0.7 & 0.1 & 1.9 & 1.1 & 0.3 & 0.3 & 0.1 & 1.7 \\
\hline Total & 53.4 & 17.2 & 27.0 & 2.3 & $18.5^{*}$ & 82.5 & 12.9 & 4.1 & 0.6 & $12.8^{*}$ \\
\hline
\end{tabular}

Note: Cells marked with an asterisk correspond to the percentages of observations in each claiming configuration.

Table 4: Change in Hours Worked per Week and the Claiming Decision

\begin{tabular}{|c|c|c|c|c|c|c|c|c|}
\hline \multirow[b]{2}{*}{ did not cl. at $\mathrm{t}$} & \multicolumn{4}{|c|}{ (husb hrs) did not claim at t+1 } & \multicolumn{4}{|c|}{ (wife hrs) did not claim at t+1 } \\
\hline & 0 & $1-30$ & $30-50$ & $50+$ & \multicolumn{2}{|c|}{$0 \quad 1-30$} & $30-50$ & \multirow{2}{*}{$\frac{50+}{0.6}$} \\
\hline 0 & 87.0 & 5.0 & 6.2 & 1.8 & 88.7 & 6.5 & 4.2 & \\
\hline $1-30$ & 19.0 & 52.6 & 23.3 & 5.2 & 20.3 & 60.0 & 15.1 & 0.6 \\
\hline $30-50$ & 11.7 & 6.6 & 72.5 & 9.2 & 12.6 & 10.6 & 72.7 & 4.0 \\
\hline $50+$ & 7.0 & 4.7 & 31.7 & 56.7 & 11.6 & 10.3 & 40.5 & 37.5 \\
\hline \multirow[t]{2}{*}{ Total } & 26.5 & 9.9 & 47.2 & 16.5 & 42.9 & 18.5 & 35.1 & 3.5 \\
\hline & \multicolumn{4}{|c|}{ (husb hrs) claimed at $t+1$} & \multicolumn{4}{|c|}{ (wife hrs) claimed at $\mathrm{t}+1$} \\
\hline did not cl. at $t$ & 0 & $1-30$ & $30-50$ & $50+$ & 0 & $1-30$ & $30-50$ & $50+$ \\
\hline 0 & 87.9 & 9.9 & 2.2 & 0 & 93.8 & 5.5 & 0.7 & 0 \\
\hline $1-30$ & 23.9 & 61.2 & 13.4 & 1.5 & 37.5 & 54.2 & 4.2 & 4.2 \\
\hline $30-50$ & 28.6 & 25.0 & 44.6 & 1.8 & 30.8 & 19.2 & 42.3 & 7.7 \\
\hline $50+$ & 14.3 & 14.3 & 57.1 & 14.3 & 33.3 & 33.3 & 0 & 33.3 \\
\hline Total & 67.7 & $\begin{array}{ll}7 & 20.7\end{array}$ & 11.0 & 0.8 & 81.0 & 13.4 & 4.3 & 1.4 \\
\hline
\end{tabular}


Table 5: Point Estimates of the Collective Retirement Model

\begin{tabular}{|c|c|c|c|c|}
\hline \multirow[b]{2}{*}{ first order coefficients } & \multicolumn{2}{|c|}{ husband } & \multicolumn{2}{|c|}{ wife } \\
\hline & est. & st.err. & est. & st.err. \\
\hline \multicolumn{5}{|l|}{ own leisure $\beta_{j}$} \\
\hline constant & 0.670 & 3.195 & $-3.409 * *$ & 0.788 \\
\hline age/10 & -0.605 & 0.504 & $0.468 * *$ & 0.129 \\
\hline severe health onset & $0.661^{*}$ & 0.369 & $0.569 * *$ & 0.227 \\
\hline mild health onset & $0.489^{*}$ & 0.299 & 0.064 & 0.133 \\
\hline partner has adls (\#) & $-0.283^{* *}$ & 0.137 & $-0.164^{* *}$ & 0.077 \\
\hline working part-time & $3.055^{* *}$ & 0.365 & $1.255^{* *}$ & 0.123 \\
\hline not working & $15.65^{* *}$ & 1.263 & $7.782^{* *}$ & 0.331 \\
\hline initial leisure/10 in 1992 & $1.023^{* *}$ & 0.102 & $0.390^{* *}$ & 0.037 \\
\hline initial leisure/10 of spouse & -0.065 & 0.054 & 0.004 & 0.024 \\
\hline initial health status & $0.435^{* *}$ & 0.101 & $0.095^{* *}$ & 0.047 \\
\hline \multicolumn{5}{|l|}{ partner leisure $\beta_{-j}$} \\
\hline constant & -2.196 & 1.949 & $-7.172^{* *}$ & 1.406 \\
\hline age/10 & $-0.812^{* *}$ & 0.297 & $0.706^{* *}$ & 0.218 \\
\hline pref. retire together & $0.419^{*}$ & 0.223 & $0.229 * *$ & 0.089 \\
\hline lenght of marriage/10 & 0.070 & 0.098 & 0.056 & 0.042 \\
\hline \multicolumn{5}{|l|}{ consumption $\log \left(\beta_{c}\right)$} \\
\hline constant & $6.398 * *$ & 0.595 & $4.862^{* *}$ & 0.334 \\
\hline age/10 & $-1.067^{* *}$ & 0.104 & $-0.877^{* *}$ & 0.062 \\
\hline severe health onset & -4.112 & 8.496 & 0.111 & 0.203 \\
\hline mild health onset & 0.040 & 0.283 & -0.173 & 0.144 \\
\hline partner has adls & $-1.260^{*}$ & 0.824 & $-1.147^{* *}$ & 0.449 \\
\hline initial health & -0.100 & 0.081 & $-0.140^{* *}$ & 0.042 \\
\hline \multicolumn{5}{|l|}{ second order $\beta_{m f}$} \\
\hline log of partner leisure & $2.683^{* *}$ & 0.357 & $-0.308^{* *}$ & 0.103 \\
\hline \multicolumn{5}{|l|}{ Weight $\mu$} \\
\hline constant & $-0.849^{* *}$ & 0.111 & & \\
\hline age difference/10 & $0.227^{* *}$ & 0.044 & & \\
\hline wage $(\mathrm{m}) / 10$ & $0.089 * *$ & 0.012 & & \\
\hline wage (f) $/ 10$ & -0.009 & 0.009 & & \\
\hline capital income/10000 & $-0.239 * *$ & 0.031 & & \\
\hline Aime $(\mathrm{m}) / 1000$ & $-0.033^{* *}$ & 0.008 & & \\
\hline Aime(f)/1000 & 0.003 & 0.009 & & \\
\hline Log likelihood & -2.021 & & & \\
\hline
\end{tabular}

Note: Coefficients with an (double) asterisk are significant at the 10 (5) percent significance level. 
Table 6: Changes in Marginal Rate of Substitutions

\begin{tabular}{lccccccc}
\hline \hline & \multicolumn{7}{c}{ quantiles } \\
Effect on marginal rate of substitution & 0.1 & 0.25 & 0.5 & 0.75 & 0.9 & 0.95 \\
\hline Severe health onsets & & & & & & \\
\hline \$ of cons. per hour of husb. leisure & 0 & 0 & 0 & 0 & 5.17 & 19.9 \\
\$ of cons. per hour of wife. leisure & 0 & 0 & 0 & 0 & 0 & 51.4 \\
\hline ADLs of spouse & & & & & \\
\hline \$ of cons. per hour of husb. leisure & 0 & 0 & 0 & 0 & 146.8 & 22476 \\
\$ of cons. per hour of wife leisure & 0 & 0 & 0 & 0 & 0 & 3660.1 \\
\hline \hline
\end{tabular}


Table 7: Observed and Predicted Distribution for 2000

\begin{tabular}{|c|c|c|c|c|c|}
\hline \multirow{2}{*}{$\begin{array}{l}\text { obs. hours per week } \\
\text { husband }\end{array}$} & \multicolumn{4}{|c|}{ wife } & \multirow[b]{2}{*}{ Total } \\
\hline & 0 & $1-30$ & $30-50$ & $50+$ & \\
\hline 0 & 35.85 & 6.74 & 7.29 & 0.45 & 50.33 \\
\hline $1-30$ & 7.74 & 3.53 & 3.30 & 0.36 & 14.93 \\
\hline $30-50$ & 10.91 & 5.50 & 9.72 & 0.73 & 26.86 \\
\hline $50+$ & 3.07 & 1.33 & 2.84 & 0.59 & 7.83 \\
\hline Total & 57.57 & 17.1 & 23.15 & 2.13 & 100 \\
\hline pre. hours per week & \multicolumn{4}{|c|}{ wife } & \\
\hline husband & 0 & $1-30$ & $30-50$ & $50+$ & Total \\
\hline 0 & 33.12 & 10.56 & 4.70 & 2.39 & 50.77 \\
\hline $1-30$ & 13.07 & 4.76 & 2.57 & 1.51 & 21.91 \\
\hline $30-50$ & 7.69 & 3.25 & 2.04 & 1.49 & 14.47 \\
\hline $50+$ & 5.86 & 2.82 & 2.11 & 2.02 & 12.91 \\
\hline $\begin{array}{l}\text { Total } \\
\text { Chi-square }(9)\end{array}$ & $\begin{array}{l}59.74 \\
433.49\end{array}$ & 21.39 & 11.42 & 7.41 & 100 \\
\hline
\end{tabular}


Table 8: Effects of Social Security Reforms on Hours worked

\begin{tabular}{c|llll}
\hline \hline $\begin{array}{c}\text { Abol. spouse ben. } \\
\text { husband }\end{array}$ & \multicolumn{5}{|c}{ wife } \\
\hline 0 & -0.1 &. & 0.02 & 0.02 \\
$1-30$ &. &. & $\cdot$ & $\cdot$ \\
$30-50$ &. &. &. & $\cdot$ \\
$50+$ &. &. &. &. \\
\hline Abol. earnings test & \multicolumn{5}{|c}{ wife } \\
husband & 0 & $1-30$ & $30-50$ & $50+$ \\
\hline 0 & -0.3 & -0.05 & $\cdot$ \\
$1-30$ & 0.03 &. &. & $\cdot$ \\
$30-50$ & 0.09 & 0.02 & 0.02 &. \\
$50+$ & 0.07 & 0.03 & 0.02 & 0.01 \\
\hline \hline
\end{tabular}

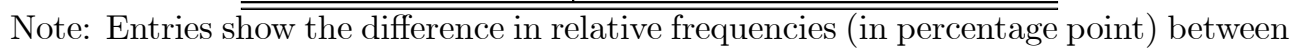
baseline (year 2000) and post reform situation. Cells with a dot contain a figure that is too small to be mentioned.

Table 9: Effects of Social Security Reforms on Claiming Decision

\begin{tabular}{c|cc}
\hline \hline $\begin{array}{c}\text { Abol. spouse ben. } \\
\text { husband }\end{array}$ & \multicolumn{2}{|c}{ wife } \\
\hline did not claim & did not claim & claimed \\
claimed & -0.07 & 0.07 \\
& & \\
\hline \hline
\end{tabular}

\begin{tabular}{c|cc}
\hline \hline $\begin{array}{c}\text { Abol. earnings test. } \\
\text { husband }\end{array}$ & did not claim & claimed \\
\hline did not claim & -0.28 & $\cdot$ \\
claimed & 0.12 & 0.16 \\
& & \\
\hline \hline
\end{tabular}

Note: Entries show the difference in relative frequencies (in percentage point) between baseline (year 2000) and post reform situation. Cells with a dot contain a figure that is too small to be mentioned. 
Table 10: Effects of Social Security Reforms on Hours worked (husband claimed/wife did not).

\begin{tabular}{c|llll}
\hline \hline Abol. spouse ben. & \multicolumn{5}{|c}{ wife did not claim } \\
husband claimed & 0 & $1-30$ & $30-50$ & $50+$ \\
\hline 0 & -0.18 & 0.03. & 0.04 & 0.02 \\
$1-30$ &. & 0.01 & 0.01 & $\cdot$ \\
$30-50$ &. &. &. & $\cdot$ \\
$50+$ &. &. &. &. \\
\hline Abol. earnings test & \multicolumn{5}{|c}{ wife did not claim } \\
husband claimed & 0 & $1-30$ & $30-50$ & $50+$ \\
\hline 0 & -0.78 & -0.025 & -0.012 & $\cdot$ \\
$1-30$ & 0.01 & 0.02 &. & $\cdot$ \\
$30-50$ & 0.3 & 0.12 & 0.07 &. \\
$50+$ & 0.3 & 0.12 & 0.08 & 0.07 \\
\hline \hline
\end{tabular}

Note: Entries show the difference in relative frequencies (in percentage point) between baseline (year 2000) and post reform situation. Cells with a dot contain a figure that is too small to be mentioned. 
Table 11: Marginal tax rates

\begin{tabular}{c|cc}
\hline \hline Taxable income $t i$ & Lower bound & Marginal rate \\
\hline$t i \leq 36,900$ & - & $15 \%$ \\
$36900<t i \leq 89,150$ & 5535 & $28 \%$ \\
$89150<t i \leq 140,000$ & 20165 & $31 \%$ \\
$140000<t i \leq 250,000$ & 35928.5 & $36 \%$ \\
$250,000<t i$ & 75528.5 & $39.6 \%$ \\
\hline \hline
\end{tabular}



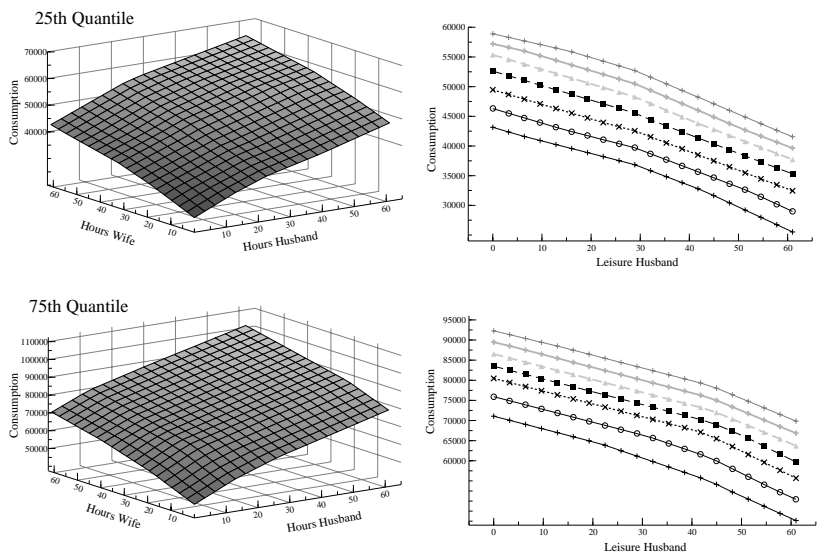

Figure 1: Budget set for a couple with a 67 years old husband
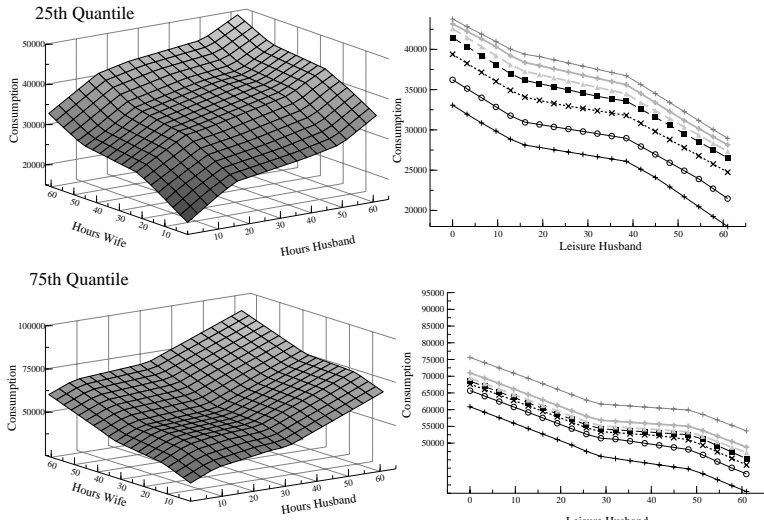

Figure 2: Budget set for a couple with a 62 years old husband 